Federal Reserve Bank of Dallas

Globalization and Monetary Policy Institute

Working Paper No. 3

http://www.dallasfed.org/assets/documents/institute/wpapers/2007/0003.pdf

\title{
International Trade in Durable Goods: Understanding Volatility, Cyclicality, and Elasticities ${ }^{*}$
}

\author{
Charles Engel \\ University of Wisconsin \\ Jian Wang \\ Federal Reserve Bank of Dallas
}

November 2007

\begin{abstract}
Data for OECD countries document: 1. imports and exports are about three times as volatile as GDP; 2 . imports and exports are pro-cyclical, and positively correlated with each other; 3. net exports are counter-cyclical. Standard models fail to replicate the behavior of imports and exports, though they can match net exports relatively well. Inspired by the fact that a large fraction of international trade is in durable goods, we propose a two-country two-sector model, in which durable goods are traded across countries. Our model can match the business cycle statistics on the volatility and comovement of the imports and exports relatively well. In addition, the model with trade in durables helps to understand the empirical regularity noted in the trade literature: home and foreign goods are highly substitutable in the long run, but the short-run elasticity of substitution is low. We note that durable consumption also has implications for the appropriate measures of consumption and prices to assess risk-sharing opportunities, as in the empirical work on the Backus-Smith puzzle. The fact that our model can match data better in multiple dimensions suggests that trade in durable goods may be an important element in open-economy macro models.
\end{abstract}

JEL codes: E32, F3, F4

\footnotetext{
* Charles Engel, Department of Economics, 1180 Observatory Drive, University of Wisconsin, Madison, WI 53706. 608- 262-3697. cengel@ssc.wisc.edu. Jian Wang, Research Department, Federal Reserve Bank of Dallas, 2200 N. Pearl Street, Dallas, TX 75201. 214-922-6471. jian.wang@dal.frb.org. We thank David Backus, Martin Boileau, Lukasz Drozd, Jonathan Heathcote, Enrique Martinez-Garcia, Mark Wynne, Kei$\mathrm{Mu} \mathrm{Yi}$, and seminar participants at Boston College, Chicago GSB, Dartmouth College, Tufts University, the Federal Reserve Bank of Dallas, and HEC/CIRPEE Real Business Cycle Conference for helpful comments. Engel acknowledges support for this research from a grant from the National Science Foundation. The views expressed in this paper are those of the authors and do not necessarily reflect the views of the Federal Reserve Bank of Dallas or the Federal Reserve System.
} 


\section{Introduction}

One of the most established empirical regularities in international business cycle analysis is the countercyclical behavior of net exports. Backus, Kehoe and Kydland $(1992,1994)$ (BKK henceforth) explain this empirical finding with the dynamics of capital formation: in the face of a positive productivity shock, the increase of investment exceeds the increase in saving. ${ }^{1}$ In contrast, the behavior of imports and exports themselves has been largely neglected in the literature. ${ }^{2}$ They are much more volatile than GDP and both are pro-cyclical, facts which are at odds with the predictions of standard models. Inspired by the evidence that a large fraction of international trade is in durable goods, we propose a two-country two-sector model, in which durable goods are traded across countries. Simulation results show that our model can match the trade sector data much better than the standard models. Our model also sheds light on two other puzzles in the literature: the elasticity puzzle and Backus-Smith puzzle.

We first document two robust empirical findings: 1. Real imports and exports are much more volatile than total output. Their standard deviations are on average about two to three times as large as GDP's in our OECD-country dataset. ${ }^{3}$ 2. Real imports and exports are pro-cyclical and also positively correlated with each other. We label the first finding "trade volatility", and the second one "positive comovement". These findings are very robust across our 25-OECD-country data. We also confirm in our dataset the well-documented negative correlation between net exports and output.

In a standard international real business cycle (IRBC) model with incomplete financial markets, we show that imports and exports are far less volatile than in the data. They are actually even less volatile than GDP. One can modify the standard IRBC model with monopolistic competition, sticky prices and monetary policy rules. This class of models is labeled as open-economy Dynamic Stochastic General Equilibrium (DSGE) models and has been used widely in open-economy policy analysis. These extensions do not help the model's performance in replicating the behavior of imports and exports. However, the IRBC and DSGE models also fail to replicate real exchange rate volatility. A natural question is whether a model with more variable exchange rates can replicate the "excessive volatility" in imports and exports. We follow recent DSGE modeling, and add a shock to the interest-parity relationship in order to increase exchange-rate volatility. ${ }^{4}$

\footnotetext{
${ }^{1}$ Raffo (2006) modifies BKK's model with a preference function proposed by Greenwood, Hercowitz and Huffman (1988) (GHH henceforth). He finds that the modified model can also replicate the counter-cyclical net exports measured at constant prices.

${ }^{2}$ The only paper that examines import and export volatility to our knowledge, is Zimmermann (1999). That paper uses exogenous exchange rate shocks to generate the volatility of imports and exports. This explanation is contradictory to the positive correlation between imports and exports. We give more details later.

${ }^{3}$ Similar results are also reported in Table 11.7 of Backus, Kehoe and Kydland (1995), Heathcote and Perri (2002), and Zimmermann (1999).

${ }^{4}$ This approach is similar to Zimmerman's (1999), which adds an exogenous source of exchange-rate volatility.
} 
We also try the "elasticity method" suggested by Chari, Kehoe and McGrattan (2002) to increase exchangerate volatility. Although a more volatile exchange rate helps to increase the volatility of imports and exports, it generates a negative correlation between imports and exports. This is at odds with the finding of "positive comovement". Import and export volatility in those models is mainly driven by the effects of fluctuations in the terms of trade. When the terms of trade (relative price of imports and exports changes) change, the imports and exports go to opposite directions. Therefore, these models generate a counterfactual strong negative correlation between the imports and exports.

We propose a model in which countries trade durable goods only. This setup is inspired by the fact that a large portion of international trade is durable goods. Baxter (1995) shows that about two thirds of trade is in durable goods (including capital goods.) Erceg, Guerrieri, and Gust (2006) document a more recent (year 2004) breakdown of US imports and exports. They find that consumer non-durables account for only $28 \%$ of non-energy imports and $25 \%$ of non-energy exports. In contrast, consumer durables and capital goods account for $32 \%$ and $30 \%$ of non-energy imports. For non-energy exports, they account for respectively, $16 \%$ and 45\%. Non-energy industrial supplies, which are used in producing durables, account for the remaining $10 \%$ of imports and $14 \%$ of exports. We find similar patterns in our OECD country dataset. Trade in durable goods on average accounts for more than $60 \%$ of imports and exports for OECD countries. The share increases to $70 \%$ after excluding raw materials and energy products in the trade. The importance of capital goods in international trade has also been documented by Eaton and Kortum (2001). Boileau (1999) examines a model with trade in capital goods to explain the volatility of net exports and the terms of trade. Erceg, Guerrieri, and Guest (2006) also emphasize that trade in capital goods helps model to replicate trade volatility. They argue that trade balance adjustment may be triggered by investment shocks from either home or foreign country and such adjustment may not cause substantial real exchange rate fluctuations. Warner (1994) finds that global investment demand has been an important determinant of U.S. exports since 1967. However, we find that a model with trade in capital goods but not consumer durables is inadequate. In order to match the volatility of the trade data, a large share of traded goods must be durable. But if we take all of those traded goods to be capital, then the model would require, for example, that the U.S. obtains almost all capital goods from imports while simultaneously exporting large quantities of capital.

Our model goes further by including both capital and durable consumption goods in international trade. ${ }^{5}$

\footnotetext{
${ }^{5}$ Baxter (1992) has durable consumption in a two-sector model. The model setup is very different form ours and is used to address different issues. Sadka and Yi (1996) build a simple small-country real-business-cycle model with durable consumption goods. They use this model to demonstrate that the increase of consumption durables due to a permanent decrease in their prices may be an important element in explaining the 1980s US trade deficits.
} 
In our two-country two-sector model, nondurable goods are nontraded. Durable consumption flows require both home and foreign durable goods varieties and capital goods are aggregated from home and foreign varieties of capital. Simulation results show that the benchmark model can successfully replicate "trade volatility" and "positive comovement". In addition, net exports in our model are counter-cyclical and as volatile as in the data. So our model can match the trade sector data much better than the standard models. This improvement is not at the cost of other desirable features of standard models. The aggregate variables such as output, consumption, investment and labor, can also match the data well.

Our benchmark model can also replicate the behavior of short- and long-run elasticities documented in the trade literature. One strand of literature estimates the long-run elasticity of substitution between the home and foreign goods from permanent relative price changes, such as from tariff reductions. Those studies usually find a large elasticity of about 8 (for instance Feenstra and Levinsohn, 1995 and Head and Ries, 2001.) But when the same elasticity is estimated from relative price fluctuations at the business cycle frequency, the estimate is much smaller - even less than one (for instance, Bergin, 2006, Heathcote and Perri, 2002.) Several studies have offered explanations for this puzzle, and ours is closely related. A common feature of the hypotheses is that the long-run elasticity of substitution is high, but the short-run elasticity is low due to some market frictions. Ruhl (2005) proposes a model in which firms have to pay a fixed cost to change their export status. Benefits from changing export status are not enough to recover the fixed cost under transitory shocks. So the elasticity of substitution between the home and foreign goods is low when shocks are transitory. However, in the face of persistent chocks, firms will pay the fixed cost and change their export status, which leads to a large increase of trade share even for a small, but permanent price change. Drozd and Nosal (2007) use the friction of international marketing to reduce the response of output to relative price changes. Ramanarayanan (2007) models this problem from the side of importers. In this model, importers use foreign goods as intermediate inputs in production. Home and foreign intermediate goods are perfectly substitutable in the long run, but switching between them in the short run is very costly. We follow the same idea in our model, where we assume that the home and foreign goods are highly substitutable in the long run, but in the short run there is a quadratic cost for adjusting the durable consumption and capital stocks. Unlike the above studies, we do not provide a micro-story for the market friction. Our contribution is quantitative. After calibrating the adjustment costs to match the volatility of durable consumption and investment, we investigate whether our model can also deliver a reasonable short-run elasticity of substitution.

When agents can trade a complete set of contingent claims, but face potentially different goods prices, in a variety of contexts models imply that relative cross-country consumption should be perfectly positively correlated with the real exchange rate. Backus and Smith (1993) demonstrate this result in a model with 
nontraded goods, while Chari, Kehoe, and McGrattan (2002) show that even a DSGE model with incomplete markets implies a strong but imperfect positive correlation. But, beginning with Backus and Smith, several studies find empirically that the correlation between relative consumption and the real exchange rate is generally low, even negative in many countries. Some recent papers offer models to explain this correlation when capital markets are not perfect, and only bonds are traded. ${ }^{6}$ Our model shares some of the features of these models, but also offers some new insight. Consumption measured in national accounts data does not capture the service flow from consumer durables. Our model does a good job of replicating the data for measured consumption, which includes purchases of new durable goods. Positive wealth shocks increase purchases of new consumer durables as well as nondurables, and drive up the relative price of nontraded (nondurable) goods, as in Benigno and Thoenissen (2007). But the consumption flow from durable goods adjusts slowly to shocks, so the behavior of "true" consumption can be quite different than that of measured consumption.

Our model's success in accounting for several aspects of international trade data suggests that it may be important to incorporate the trade in durable goods when constructing an open-economy model for policy analysis. There are several challenges remaining, however. A well-known departure of the IRBC model from the data is that cross-country outputs have low correlation in those models, while this correlation is positive and relatively high in the data. Our model provides little insight on this issue. In this paper, we also take trade in durable goods as exogenously given. Future work might endogenize the durability of traded goods, relating the types of goods traded to the cost of storage and time to ship.

The remainder of the paper is organized as follows: Section 2 displays statistics on "trade volatility" and "positive comovement". We show that the standard models and their simple extensions cannot simultaneously replicate those empirical findings. Section 3 describes our two-country two-sector benchmark model. Section 4 explains our calibration of the model. Section 5 shows simulation results of the benchmark model and Section 6 concludes.

\section{Empirical Findings and Performance of Standard Models}

In this section, we first show some facts about international real business cycles: 1 . Real imports and exports are about two to three times as volatile as GDP. 2. Both real imports and exports are pro-cyclical and positively correlated with each other. 3. Real net exports are counter-cyclical. Then we investigate whether standard models in the literature can replicate those features. We also present evidence that trade in durable

\footnotetext{
${ }^{6}$ For instance, Corsetti, Dedola and Leduc (forthcoming), and Benigno and Thoenissen (2007).
} 
goods accounts for a large portion of imports and exports in OECD countries.

\section{$2.1 \quad$ Empirical Findings}

Our data-set includes quarterly real GDP, real imports, real exports, and real net exports of OECD 25 countries during the period between 1973Q1 and 2006Q3. ${ }^{7}$ The data are from OECD Economic Outlook database. All variables are logged except net exports ${ }^{8}$ and H-P filtered with a smoothing parameter of 1600.

Table 1 shows the volatility of those variables. The standard deviation of GDP on average, is $1.51 \%$. Both real imports and exports are much more volatile than GDP. On average, the imports are 3.3 times, and exports are 2.7 times as volatile as GDP. ${ }^{9}$ This result is not driven by outliers. The sample median is very close to the sample mean. The volatilities of imports and exports in the US are close to the sample mean. However, the ratio of net exports to GDP in the US is less volatile than it is in any other countries.

Table 2 reports comovement of real imports and real exports with GDP. Two things stand out. First, both imports and exports are pro-cyclical. This result is very robust: the imports are positively correlated with GDP in all 25 countries. The average correlation is 0.63 . The same is true for exports except in two countries: Denmark and Mexico. The average correlation between exports and GDP is 0.39. Second, imports and exports are positively correlated in all countries except Australia, Mexico, New Zealand and Spain. The average correlation between imports and exports is 0.38 . In this table, we also confirm a well-documented finding in previous studies: net exports are counter-cyclical. This is true in all countries except Austria and Hungary. ${ }^{10}$ The average correlation between net exports and GDP is -0.24 .

\subsection{Performance of Standard Models}

We investigate whether some standard models can replicate the facts presented in Tables 1 and 2. Table 3 shows simulation results for these models. These simulations demonstrate that the standard models and their extensions cannot replicate trade volatility and positive comovement simultaneously. Since the model setups are very standard in the literature, we leave them in the appendix.

We consider two types of models: the IRBC model and the DSGE model. We use exactly the structure of the bond-economy model in Heathcote and Perri (2002) as our standard IRBC model (labeled HP in Table 3.) This model has the same structure as BKK's model, but limits the financial market to a real-bond market

\footnotetext{
${ }^{7}$ Due to data limitation, Austria starts from 1988Q1, Czech Republic starts from 1993Q1, and Hungary starts from 1991 Q1. The data of Germany are for West Germany only which end in 1991Q1. The data after unification (1991Q1-2006Q3) show similar patterns.

${ }^{8}$ Following the literature, we divide the net exports by GDP.

${ }^{9}$ This excessive volatility of imports and exports has also been documented in Backus, Kehoe, and Kydland (1995), Heathcote and Perri (2002), and Zimmermann (1999).

${ }^{10}$ For instance, see Backus, Kehoe and Kydland (1992, 1994, 1995).
} 
only. Baxter and Crucini (1995) compare this incomplete financial market model with the model with perfect risk-sharing and find they behave very similarly if the productivity shock is not extremely persistent or the cross-country spillover of productivity shocks is high. Table 3 also reports results for the DSGE model. This is the extension of the IRBC model that assumes monopolistic competition, trade in nominal bonds, Calvo staggered price setting, and a monetary policy (Taylor) rule. Those models are often used in the studies of monetary policy in open economies.

GHH is the DSGE model with the preference function proposed by Greenwood, Hercowitz and Huffman (1988). The function takes a form of

$$
u_{t}=\frac{\left(C_{t}-\rho L_{t}^{\nu}\right)^{1-\sigma}}{1-\sigma}
$$

where $C_{t}$ is the consumption and $L_{t}$ is the labor supply. We use the same class of utility function in our benchmark model. We include this model to show that our benchmark model results are not driven by this choice of utility function. We also report the results for two more extensions of the DSGE model: the model with low intertemporal elasticity of substitution (Lo-elast) and one with an uncovered interest rate parity shock (UIP). The standard international RBC model and DSGE models cannot replicate the volatility of the real exchange rate. We use those two methods to increase this volatility to see if it helps the model's performance in matching the behavior of imports and exports.

Panel A of Table 3 reports the standard deviations of aggregate variables relative to that of GDP. In our standard IRBC model (HP), imports and exports are even less volatile than GDP. The same discrepancy has also been reported in Table 2 of Heathcote and Perri (2002). ${ }^{11}$ They find that the assumption of financial autarky can improve the volatility of imports and exports in a very limited way. The added features in DSGE model and GHH models cannot solve this problem. Imports and exports are still far less volatile than what they are in the data. However, the GHH utility function does make the volatility of net exports much closer to the data. This follows because imports and exports are more volatile (due to more variable consumption in the GHH model), and imports and exports are less correlated than what they are in the DSGE model.

Panel B shows the correlations of real imports, real exports, and real net exports with GDP, as well as the correlation between real imports and exports. Imports and exports are measured by their steady state prices (constant price). The models of HP, DSGE and GHH match the data in that real imports and exports are pro-cyclical and positively correlated with each other. Net exports are counter-cyclical in these models. That is, the standard models can replicate the "positive comovement" feature, though they fail the

\footnotetext{
${ }^{11}$ Zimmermann (1999) finds similar results in a sticky price model.
} 
"trade volatility". ${ }^{12}$ Panel C reports the same statistics as Panel B, but imports, exports and net exports are measured in terms of final consumption goods, instead of constant prices. The results are similar to those in Panel B.

Besides the volatility of imports and exports relative to GDP, another feature missing from the standard DSGE model is the high volatility of the real exchange rate. A natural question is whether we can increase the volatility of imports and exports in a model with more volatile real exchange rates. We follow Chari, Kehoe and McGrattan's (2002) "elasticity method" to increase real exchange rate volatility by decreasing the value of the intertemporal elasticity of substitution $1 / \sigma$. Some authors have also used an uncovered interest rate parity (UIP) shock to generate exchange rate variations in DSGE models. ${ }^{13}$ In our simulation results, we find that the volatilities of real imports, exports and the exchange rate all increase in those models. Under certain calibrations of the UIP shock, the model can also replicate the pro-cyclical movement of imports and exports, though the correlation between exports and output is nearly zero. However, there is a striking departure of these models from the data: real imports and exports are highly negatively correlated in those models.

Figure 1 shows the production structure in the standard models. Home and foreign intermediate goods are used to produce final goods. The final goods are used for consumption and investment. There are two factors affecting the volatility of imports: 1 . the volatility of demand for final goods and, 2. the substitution between home and foreign goods. Under the standard calibration, the majority (about 75\%) of final goods (and therefore imports) goes to consumption. Consumption is less volatile than GDP in the data. So if we want to match the volatility of consumption, demand for final goods will not be very volatile. Given the low volatility of demand for final goods, we can still have very volatile imports and exports if there is a lot of substitution between home and foreign goods. This is actually what the high elasticity and the UIP models do.

Exchange rate movements induce fluctuations in the relative price of imports and exports. In return, the substitution between home and foreign goods increases the volatility of imports and exports. But when the terms of trade changes, the imports and exports move in opposite directions. So this method produces a negative correlation between imports and exports, which is contradictory to the data. Baxter and Stockman (1989) find little evidence of systematic difference in the volatilities of real imports and exports when countries switch from fixed to flexible exchange rate regimes, though the real exchange rates became substantially more

\footnotetext{
${ }^{12}$ Raffo (2006) finds that the real net exports measured with constant prices are pro-cyclical under the standard utility function of $u_{t}=\frac{\left[C_{t}^{\mu}\left(1-L_{t}\right)^{1-\mu}\right]^{1-\sigma}}{1-\sigma}$. We find that this conclusion may be sensitive to the volatility of investment and the elasticity of substitution between home and foreign goods.

${ }^{13}$ For instance, see Kollmann (2004), Wang(2007).
} 
variable during this period. This finding also suggests that the high volatility of international trade flows is unlikely to come from the exchange rate fluctuations.

\subsection{Trade in Durable Goods in OECD Countries}

Here we present some descriptive statistics on trade flows that help to motivate our model of trade in durables. We obtain our 25 OECD country data from NBER-UN World Trade Data and use the latest available data (year 2000) to calculate the share of durable goods in international trade. The original data are at 4-digit SITC levels. We aggregate them into 1- and 2-digit levels for each country. Then we use the information of the SITC classifications to classify imports and exports into durable and nondurable goods.

At the 1-digit SITC level, there are 10 categories (0-9). Categories 0 (FOOD AND LIVE ANIMALS), 1 (BEVERAGES AND TOBACCO), and 4 (ANIMAL AND VEGETABLE OILS, FATS AND WAXES) are obviously nondurable goods. It is also straightforward that category 7 (MACHINERY AND TRANSPORT EQUIPMENT) belongs to durable goods. Category 2 is raw materials that exclude fuels such as petroleum. Category 3 contains energy products such as coal, petroleum, gas, etc. The remaining categories however are difficult to classify. This is particularly true for category 5 (CHEMICALS AND RELATED PRODUCTS, N.E.S.). Even if we go down to the 3-digit level, it is still unclear which categories belong to durable goods. We find that this category includes many nondurable goods, such as fertilizers, medicines, cleaning products, etc. To avoid exaggerating the share of durable goods, we put the whole category 5 into nondurable goods. But we note that this category does include some durable goods, such as plastic tubes, pipes, etc.

For categories 6, 8 and 9, we go down to the SITC 2-digit levels for more information about the durability of goods. Category 6 (MANUFACTURED GOODS CLASSIFIED CHIEFLY BY MATERIALS) classifies goods according to their materials. We assume that goods produced from leather, rubber, or metals are durables (61-62 and 66-69). Goods produced from wood (other than furniture), paper, or textile (63-65) are nondurables. Category 8 includes other manufactured products that are not listed in categories 6 and 7 . We assume that construction goods (81), furniture (82), professional instruments (87), photographic equipments (88) are durable goods. Travel goods (83), clothing (84), footwear (85) and remaining goods (89) are classified as nondurables. Category 9 includes products that are not classified elsewhere. In this category, we assume that coins and gold (95-97) are durables. All remaining products are classified as nondurables.

Table 4 reports the share of durable goods in imports and exports in our 25 OECD country dataset. On average durable goods account for about $60 \%$ of total imports and exports in these countries. If we exclude raw materials (SITC 2) and energy products (SITC 3), the share increases to $70 \%$ (right panel of 
Table 4). We find that about three quarters of trade is in durable goods in the US if we exclude energy products, which is in line with the finding of Erceg, Guerrieri, and Gust (2006). We note some outliers for exports. More than $50 \%$ of exports in Australia and New Zealand are in categories zero (FOOD AND LIVE ANIMALS) and two (CRUDE MATERIALS, INEDIBLE, EXCEPT FUELS). 65\% of exports in Iceland are FOOD AND LIVE ANIMALS. Norway exports a significant amount of energy products. After we exclude raw materials and energy products, Australia and Norway become close to our sample mean. Iceland and New Zealand still export a much lower share of durable goods than other OECD countries. But our overall results confirm that durable goods account for a large portion of international trade for OECD countries. In particular, category 7 (MACHINERY AND TRANSPORT EQUIPMENT) on average accounts for more than $40 \%$ of trade for OECD countries.

\section{A Two-country Benchmark Model}

There are two symmetric countries in our model, Home and Foreign. We depart from the standard models in Section 2.2 by having two production sectors in each country: the nondurable good and durable good sectors. All firms are perfectly competitive with flexible prices. Nondurable goods can only be used for domestic consumption. Durable goods are traded across countries and used for durable consumption and capital accumulation. Because of the symmetry between these two countries, we describe our model focusing on the Home country. ${ }^{14}$

Our modeling strategy is motivated by the empirical regularities discussed in Section 2.1. As we have noted, in order to explain the high volatility of imports and exports, it is not promising to rely on the response of these variables to price changes. That would tend to make imports and exports negatively correlated, but in fact they are positively correlated. Instead, we note that changes in capital stocks can be very volatile in response to persistent changes in productivity. It is well known that investment is very volatile and pro-cyclical. However, it would be unrealistic to attribute all of the movements in imports and exports to trade in capital goods. In order to match the movements in trade volumes, we would need to ascribe an unrealistically high share of trade to trade in capital goods.

Instead, we add trade in durable consumption goods to the model. This is a plausible avenue to explore, because Baxter (1995) has shown that about two-thirds of trade is in either capital goods or durable consumption goods. We suspect that in fact this is an underestimate of the share of durables, since many goods that have characteristics of durables - such as clothing - are classified as nondurables. It is intuitive

\footnotetext{
${ }^{14}$ We list all equilibrium conditions for both countries in Appendix A.2.
} 
that a large fraction of trade is in durables. Nondurable goods are typically more perishable, and thus more expensive to ship than durables.

The standard RBC models are able to capture the pro-cyclicality of imports and exports, and the countercyclicality of the trade balance by introducing capital goods. But they are unable to match the volatility because most trade is in consumption goods, so the fraction of trade accounted for by investment goods is too small to account for the overall volatility of trade volumes. However, recognizing that much of trade in consumption goods is trade in consumer durables, we are able to simultaneously reconcile the volatility and cyclical behavior of imports and exports.

We are able to match the business cycle facts on trade without giving up realism in other dimensions, particularly in the characteristics of consumption behavior over the business cycle. That is because we recognize that a large fraction of consumption is in services, which we model as a nondurable nontraded good.

Trade in capital goods and consumer durables would introduce too much volatility in trade if we did not allow for some sort of installation cost. This is a well-known feature of international RBC models. But this also allows us to build a model consistent with another widely-recognized fact: that trade elasticities are higher in the long run in response to persistent shocks than they are in the short run. In our model, home and foreign durable consumption and capital goods are close substitutes, but the sensitivity over the business cycle to relative price changes is low because of these costs of adjustment.

In addition, we introduce an iceberg cost of trade. Here, we want to capture the idea that there is "home bias" in consumption of durables, as well as in the use of capital goods in production. Especially for large economic areas such as the US or the European Union, imports are a relatively small component of the overall consumption basket, or mix of inputs used in production. Because we model traded goods as being highly substitutable in the long run, it does not seem natural to simultaneously introduce home bias directly into the utility function or production function. Instead, and consistent with much of the recent literature in trade, we posit that there are costs to trade which lead to this home bias even in the long run.

We note that there is a tension in modeling the behavior of trade volumes over the business cycle. Imports and exports are pro-cyclical and their standard deviation (in logs) is much larger than that of GDP. At the same time, they are apparently not very responsive in the short run to price changes. The model of consumer durables and investment goods captures these features for reasonable parameter values. We discuss the calibration in Section 4 below, after the presentation of the model. 


\subsection{Firms}

There are two production sectors in each country: the nondurable good sector and durable good sector. Nondurable goods in the Home country are produced from capital and labor according to

$$
Y_{H t}^{N}=A_{H t}^{N}\left(K_{H t}^{N}\right)^{\chi}\left(L_{H t}^{N}\right)^{1-\chi},
$$

where $A_{H t}^{N}$ and $L_{H t}^{N}$ are respectively the TFP shock and labor in the nondurable good sector. Capital $K_{H t}^{N}$ is a CES composite of Home- and Foreign-good capital

$$
K_{H t}^{N}=\left(\alpha^{\frac{1}{\gamma}}\left(K_{H t}^{N H}\right)^{\frac{\gamma-1}{\gamma}}+(1-\alpha)^{\frac{1}{\gamma}}\left(K_{H t}^{N F}\right)^{\frac{\gamma-1}{\gamma}}\right)^{\frac{\gamma}{\gamma-1}}
$$

where in the notation such as $K_{i t}^{j k}$, we use the subscript $i$ to denote the country in which the capital is used, the first superscript $j$ to denote the sector (nondurable or durable) and the second superscript $k$ to denote the origin of the good. For instance, $K_{H t}^{N H}$ is the Home-country produced durable good that is used in the nondurable good sector of the Home country.

The firm buys labor and rents capital from households in competitive markets. For given wage $\left(W_{H t}\right)$ and rental price of capital $\left(R_{H t}^{N H}\right.$ and $\left.R_{H t}^{N F}\right)$, the firm chooses capital and labor to minimize the cost of production. The nondurable good market is also competitive, so the price of nondurable goods $P_{H t}^{N}$ is equal to the marginal cost

$$
P_{H t}^{N}=\left(A_{H t}^{N}\right)^{-1}\left(R_{H t}^{N}\right)^{\chi} W_{H t}^{1-\chi} \chi^{-\chi}(1-\chi)^{\chi-1}
$$

From the firm's cost minimization problem, we find the demand of capital and labor

$$
\begin{aligned}
& K_{H t}^{N H}=\alpha\left(\frac{R_{H t}^{N H}}{R_{H t}^{N}}\right)^{-\gamma} K_{H t}^{N} \\
& K_{H t}^{N F}=(1-\alpha)\left(\frac{R_{H t}^{N F}}{R_{H t}^{N}}\right)^{-\gamma} K_{H t}^{N} \\
& K_{H t}^{N}=\chi P_{H t}^{N} Y_{H t}^{N} / R_{H t}^{N} \\
& L_{H t}^{N}=(1-\chi) P_{H t}^{N} Y_{H t}^{N} / W_{H t},
\end{aligned}
$$

where $R_{H t}^{j k}$ is the rental price of country- $k$ 's capital goods in sector $j$ and the shadow rental price of aggregate 
capital $R_{H t}^{N}$ is defined as

$$
R_{H t}^{N}=\left[\alpha\left(R_{H t}^{N H}\right)^{1-\gamma}+(1-\alpha)\left(R_{H t}^{N F}\right)^{1-\gamma}\right]^{\frac{1}{1-\gamma}} .
$$

Durable goods in the Home country are also produced from capital and labor

$$
Y_{H t}^{D}=A_{H t}^{D}\left(K_{H t}^{D}\right)^{\epsilon}\left(L_{H t}^{D}\right)^{1-\epsilon}
$$

The capital stock in the durable good sector $K_{H t}^{D}$ is composed of the Home- and Foreign-good capital and follows the same format as that in the nondurable good sector

$$
K_{H t}^{D}=\left(\alpha^{\frac{1}{\gamma}}\left(K_{H t}^{D H}\right)^{\frac{\gamma-1}{\gamma}}+(1-\alpha)^{\frac{1}{\gamma}}\left(K_{H t}^{D F}\right)^{\frac{\gamma-1}{\gamma}}\right)^{\frac{\gamma}{\gamma-1}}
$$

The capital is not mobile across sectors though we assume labor can move freely from one sector to another.

From the firm's cost minimization problem, we find similar conditions as in the nondurable good sector

$$
\begin{aligned}
& K_{H t}^{D H}=\alpha\left(\frac{R_{H t}^{D H}}{R_{H t}^{D}}\right)^{-\gamma} K_{H t}^{D} \\
& K_{H t}^{D F}=(1-\alpha)\left(\frac{R_{H t}^{D F}}{R_{H t}^{D}}\right)^{-\gamma} K_{H t}^{D} \\
& K_{H t}^{D}=\epsilon P_{H t}^{D H} Y_{H t}^{D} / R_{H t}^{D} \\
& L_{H t}^{D}=(1-\epsilon) P_{H t}^{D H} Y_{H t}^{D} / W_{H t},
\end{aligned}
$$

where the shadow rental price of aggregate capital $R_{H t}^{D}$ is defined as

$$
R_{H t}^{D}=\left[\alpha\left(R_{H t}^{D H}\right)^{1-\gamma}+(1-\alpha)\left(R_{H t}^{D F}\right)^{1-\gamma}\right]^{\frac{1}{1-\gamma}} .
$$

The price of durable goods is equal to the marginal cost

$$
P_{H t}^{D H}=\left(A_{H t}^{D}\right)^{-1}\left(R_{H t}^{D}\right)^{\epsilon} W_{H t}^{1-\epsilon} \epsilon^{-\epsilon}(1-\epsilon)^{\epsilon-1} .
$$

\subsection{Households}

In the Home country, the representative household supplies labor, accumulates and rents capital to firms, chooses nondurable consumption and accumulates durable consumption stock to maximize expected lifetime 
utility

$$
E_{t} \sum_{j=0}^{\infty} \beta^{j} u\left(D_{H t+j}, C_{H t+j}, L_{H t+j}\right),
$$

where the period utility $u\left(D_{H t+j}, C_{H t+j}, L_{H t+j}\right)$ is a function of durable consumption $\left(D_{H t+j}\right)$, nondurable consumption $\left(C_{H t+j}\right)$, and labor supply $\left(L_{H t+j}\right)$. The period utility function takes the form of

$$
u_{t}=\frac{\left[\left(\mu^{\frac{1}{\zeta}} D_{H t}^{\frac{\zeta-1}{\zeta}}+(1-\mu)^{\frac{1}{\zeta}} C_{H t}^{\frac{\zeta-1}{\zeta}}\right)^{\frac{\zeta}{\zeta-1}}-\rho L_{H t}^{\nu}\right]^{1-\sigma}}{1-\sigma} .
$$

It is an augmented GHH utility function with consumption as a CES composite of durable and nondurable consumption. The stock of durable consumption is a function of the Home $\left(D_{H t}^{H}\right)$ and Foreign $\left(D_{H t}^{F}\right)$ durable consumption stocks

$$
D_{H t}=\left[\psi^{\frac{1}{\theta}}\left(D_{H t}^{H}\right)^{\frac{\theta-1}{\theta}}+(1-\psi)^{\frac{1}{\theta}}\left(D_{H t}^{F}\right)^{\frac{\theta-1}{\theta}}\right]^{\frac{\theta}{\theta-1}}
$$

where $\psi$ is the weight of Home durable goods in the durable consumption stock and $\theta$ is the elasticity of substitution between the Home and Foreign durable goods. The law of motion for durable consumption is

$$
\begin{aligned}
& D_{H t+1}^{H}=\left(1-\delta_{D}\right) D_{H t}^{H}+d_{H t}^{H} \\
& D_{H t+1}^{F}=\left(1-\delta_{D}\right) D_{H t}^{F}+d_{H t}^{F},
\end{aligned}
$$

where $d_{H t}^{H}$ and $d_{H t}^{F}$ are respectively the Home and Foreign durable consumption goods purchased by the household at time $t$. As in Erceg and Levin (2007) and Whelan (2003), the household also has to pay an adjustment cost when adjusting the durable consumption stock

$$
\begin{aligned}
\Delta_{H t}^{H} & =\frac{1}{2} \phi_{1}\left(d_{H t}^{H}-\delta_{D} D_{H t}^{H}\right)^{2} / D_{H t} \\
\Delta_{H t}^{F} & =\frac{1}{2} \phi_{1}\left(d_{H t}^{F}-\delta_{D} D_{H t}^{F}\right)^{2} / D_{H t},
\end{aligned}
$$

where $\Delta_{H t}^{H}$ and $\Delta_{H t}^{F}$ are respectively the costs of changing Home- and Foreign-good durables. ${ }^{15}$

If there were no adjustment costs to durables, durable consumption purchases would be very volatile in response to shocks. Empirical work (see for example, Mankiw (1982) and Gali (1993)), finds that durable

\footnotetext{
${ }^{15}$ Adjustment costs are scaled by the total durable consumption stock $\left(D_{H t}\right)$ so that the cost of adding new durable consumption $\left(d_{H t}^{H}-\delta_{D} D_{H t}^{H}\right.$ and $\left.d_{H t}^{F}-\delta_{D} D_{H t}^{F}\right)$ is the same for both types of durable consumption. The same format is also used in the capital adjustment cost functions.
} 
consumption adjusts more smoothly and is less volatile than a model with no adjustment costs would imply. Gali suggests that adjustment costs may account for the excess smoothness of durable consumption, and indeed Startz (1989) finds that adjustment costs can account for the behavior of durable consumption in a permanent income model. Bertola, Guiso, and Pistaferri (2005) find support on micro level data for a model with a fixed cost of adjustment. Aggregate consumption is not likely to exhibit the same lumpiness as micro data, so we adopt the standard quadratic adjustment cost formulation (as in Startz(1989).)

The law of motion for capital stocks in the durable and nondurable sectors follows the standard form

$$
K_{H t+1}^{j k}=(1-\delta) K_{H t}^{j k}+I_{H t}^{j k}
$$

where $j \in\{D, N\}$ and $k \in\{H, F\}$. We follow the literature to include capital adjustment costs in our model. In the Home country, it takes the following form

$$
\Lambda_{H t}^{j k}=\frac{1}{2} \phi_{2}\left(I_{H t}^{j k}-\delta K_{H t}^{j k}\right)^{2} / K_{H t}^{j}
$$

where $j \in\{D, N\}$ and $k \in\{H, F\}$. Symmetric adjustment costs exist in the Foreign country.

The Home and Foreign countries can only trade real bonds, which are in terms of the Home durable goods. It is well known that transient shocks have permanent wealth effect in an open-economy model with incomplete international financial market. To make our model stationary, we follow Heathcote and Perri (2002) to introduce a quadratic bond holding cost $\left(\frac{1}{2} \Phi B_{H t+1}^{2}\right)$. $\Phi$ is very close to zero and the cost does not affect any results in our model. ${ }^{16}$

For the given production structure, the household's budget constraint is

$$
\begin{aligned}
P_{H t}^{N} C_{H t} & +P_{H t}^{D H}\left(d_{H t}^{H}+\Delta_{H t}^{H}+I_{H t}^{N H}+\Lambda_{H t}^{N H}+I_{H t}^{D H}+\Lambda_{H t}^{D H}+\frac{B_{H t+1}}{1+i_{t}}+\frac{1}{2} \Phi B_{H t+1}^{2}\right) \\
& +P_{H t}^{D F}\left(d_{H t}^{F}+\Delta_{H t}^{F}+I_{H t}^{N F}+\Lambda_{H t}^{N F}+I_{H t}^{D F}+\Lambda_{H t}^{D F}\right) \\
& \leq W_{H t} L_{H t}+P_{H t}^{D H} B_{H t}+R_{H t}^{N H} K_{H t}^{N H}+R_{H t}^{N F} K_{H t}^{N F}+R_{H t}^{D H} K_{H t}^{D H}+R_{H t}^{D F} K_{H t}^{D F}
\end{aligned}
$$

where $P_{H t}^{D F}$ is price of Foreign-country produced durable goods, which is in terms of the Home country's currency. $i_{t}$ is the return to real bond $B_{H t+1}$. Subject to this budget constraint, the household maximizes expected lifetime utility.

\footnotetext{
${ }^{16}$ There are several other techniques used in the literature to deal with this nonstationarity problem. See Schmitt-Grohé and Uribe (2003) for more discussions.
} 


\subsection{Other Equilibrium Conditions}

Nondurable goods can only be used for domestic nondurable consumption. So the market clearing condition for Home nondurable goods is

$$
Y_{H t}^{N}=C_{H t} .
$$

Durable goods are used for durable consumption and capital investment in both countries. We also assume there is an iceberg trade cost for international trade. Only a fraction $1-\tau$ of goods arrives in the destination country, so the market clearing condition for Home durable goods is

$$
\begin{aligned}
Y_{H t}^{D}= & d_{H t}^{H}+\Delta_{H t}^{H}+I_{H t}^{N H}+\Lambda_{H t}^{N H}+I_{H t}^{D H}+\Lambda_{H t}^{D H}+\frac{1}{2} \Phi B_{H t+1}^{2} \\
& +\frac{d_{F t}^{H}+\Delta_{F t}^{H}+I_{F t}^{N H}+\Lambda_{F t}^{N H}+I_{F t}^{D H}+\Lambda_{F t}^{D H}+\frac{1}{2} \Phi B_{F t+1}^{2}}{1-\tau} .
\end{aligned}
$$

The labor and bond markets clearing conditions are

$$
\begin{gathered}
L_{H t}=L_{H t}^{N}+L_{H t}^{D} \\
B_{H t}+B_{F t}=0 .
\end{gathered}
$$

We assume that after taking into account the trade cost, the law of one price holds

$$
\begin{gathered}
P_{H t}^{D F}=\frac{S_{t} P_{F t}^{D F}}{1-\tau} \\
\frac{P_{H t}^{D H}}{S_{t}(1-\tau)}=P_{F t}^{D H},
\end{gathered}
$$

where $P_{H t}^{D F}$ is the price of Foreign durable goods in the Home country. $S_{t}$ is the nominal exchange rate defined as the value of one unit of Foreign currency in terms of the Home currency.

In section 5, we report real exchange rates based on the consumer price index (CPI). In the Home country, the CPI is defined by:

$$
P_{H t}=\left(P_{H t}^{N}\right)^{\omega_{1}}\left(P_{H t}^{D H}\right)^{\omega_{2}}\left(P_{H t}^{D F}\right)^{\omega_{3}}
$$

where $\omega_{1}$ is the steady-state expenditure share of nondurable consumption. $\omega_{2}$ and $\omega_{3}$ are respectively the steady-state expenditure shares of Home and Foreign durable consumption. This is not the same as 
the utility based CPI, but is closer to the CPI measure used in national accounts. The CPI deflated real exchange rate is defined by

$$
Q_{t}=\frac{S_{t} P_{F t}}{P_{H t}}
$$

To solve our model, we divide all nominal prices in the Home country by the price of nondurable goods $\left(P_{H t}^{N}\right)$. That is, we use the nondurable good as numeraire. In the Foreign country, all nominal prices are divided by the price of Foreign nondurable goods $\left(P_{F t}^{N}\right)$.

\section{Calibration}

We calibrate our model such that in the steady state, the structure of the economy is the same as in Figure 2. Details about how to solve the steady state can be found in Appendix A.2.2. In our benchmark economy, nondurable goods account for $60 \%$ of total output and durable goods account for the remaining $40 \%$. Among the durable goods, half of them are used for consumption (equivalent to $20 \%$ of total output) and the other half are used for investment (equivalent to $20 \%$ of total output). ${ }^{17}$ Among durable consumption goods, $65 \%$ are used for domestic consumption (equivalent to $13 \%$ of total output) and $35 \%$ are used for exports (equivalent to $7 \%$ total output). Among durable investment goods, $70 \%$ are used for domestic investment (equivalent to $14 \%$ of total output) and $30 \%$ are used for exports (equivalent to $6 \%$ of total output). In this economy, the investment accounts for $20 \%$ of total output and the consumption (durable plus nondurable) accounts for the remaining $80 \%$. The trade share of output is $13 \%$. Those features match the US data closely.

Table 5 shows parameter values that we use to match our benchmark model with the described economy structure. We set the shares of home goods in capital $(\alpha)$ and durable consumption $(\psi)$ at $50 \%$. That is, there is no home bias exogenously built in our economy structure. Instead, we generate the observed low trade share from the iceberg trade cost $\tau$. We will discuss this more later. As in Backus, Kehoe, and Kydland (1992), the capital share in production $(\chi=\epsilon)$ is set to $36 \%$, and the subjective discount factor is set to 0.99 , which gives a $4 \%$ annual real interest rate. The depreciation rate of durable consumption $\left(\delta_{D}\right)$ is set to 0.05 , which implies a $20 \%$ annual depreciation rate for consumption durables. A similar depreciation rate has been used in Bernanke (1985) and Baxter (1996).

Given those parameters, we choose other parameters to match the economy structure as in Figure 2 . We

\footnotetext{
${ }^{17}$ Durable consumption in our calibration is higher than the US data, which is about $15 \%$ of output. However, as we have mentioned, many goods with characteristics of durables-such as shoes and clothing-are classified as nondurables in the data.
} 
first choose the preference parameter $\mu$ and the depreciation rate of capital $(\delta)$ jointly to match the relative size of durable and nondurable good sectors, and the size of investment in durable goods. $\mu$ is set to 0.23 and $\delta$ is set to 0.013 such that 1 . the durable good sector accounts for $40 \%$ of total output and, 2 . the investment accounts for $50 \%$ of durable goods, or equivalently $20 \%$ of total output. Consumption durables account for the remaining $50 \%$ of durable goods, or equivalently $20 \%$ of total output.

The trade $\operatorname{cost}(\tau)$ and the elasticity of substitution between the home and foreign goods are calibrated to match two empirical findings: 1 . the trade share of total output is about $13 \%$; 2 . the long-run elasticity of substitution between the home and foreign goods is high. In our calibration, the long-run elasticity of substitution between the home and foreign capital $(\gamma)$ is set to 9.1. The elasticity of substitution between the home and foreign durable consumption $(\theta)$ is set to 6.85 . In the steady state, the trade in capital goods (durable consumption goods) accounts for $46 \%$ (54\%) of total trade. The above calibration of $\gamma$ and $\theta$ implies an overall elasticity of 7.9 , which is the same as in Head and Reis (2001). ${ }^{18}$ The trade cost $(\tau)$ is calibrated to 0.1 , that is, $90 \%$ of goods arrive in their destination countries in the international trade. For given $\gamma$ and $\theta$, this trade cost generates a trade share of $13 \%$.

We use different values for $\gamma$ and $\theta$ to generate different home bias levels for capital and durable consumption. Capital is more biased towards home goods than durable consumption (70\% vs 65\%). For given trade cost, the degree of home bias increases with the elasticity of substitution. So we assign a higher elasticity of substitution to capital goods. Alternatively, we can assume the same elasticity of substitution, but higher trade cost for capital goods. In either method, capital can have a higher level of home bias than durable consumption. We used the first method because it matches a pattern observed in the data. For given decrease in trade cost, the first method predicts that the share of investment goods in international trade increases relative to the share of durable consumption. Intuitively, the investment goods are more substitutable across countries than durable consumption under this setup. So when the trade cost decreases, there is more substitution for investment goods than for durable consumption. As a result, the share of investment goods in the trade increases. Figure 3 plots this prediction from the model. The same pattern is also found in the US data: from 1994 to 2006, the share of capital goods except automotive in total export goods increased from $34.4 \%$ to $45.1 \% .^{19}$

The preference parameters $\sigma$ and $\nu$ are set to their standard levels used in the GHH utility function. The parameter $\rho$ is chosen such that the labor supply is one third in the steady state. We assume that the elasticity

\footnotetext{
${ }^{18} 9.1 \times 46 \%+6.85 \times 54 \% \approx 7.9$.

${ }^{19}$ The data are from Haver Analytics (US International Transactions). Of course, this pattern is also consistent with another explanation: the trade cost decreases more for capital goods than for durable consumption goods.
} 
of substitution between the durable and nondurable consumption is low $(\zeta=1.1) .{ }^{20}$ The adjustment cost parameters of durable consumption $\left(\phi_{1}\right)$ is chosen to match the volatility of durable consumption, which is about three times as volatile as output in the data. The adjustment cost of capital stock $\left(\phi_{2}\right)$ is calibrated to match the volatility of investment, which is about three times as volatile as output in the data.

We follow Erceg and Levin (2007) in calibrating the productivity shocks in the durable and nondurable goods sectors. However, there is no information about the cross-country spillovers of those shocks in their closed-economy model. Empirical findings usually suggest small cross-country spillovers. For instance, Baxter and Crucini (1995) find no significant international transmission of shocks, except for possible transmission between US and Canada. In Kollman's (2004) estimate between the US and three EU countries, the spillover is 0.03. In Corsetti, Dedola, and Leduc (forthcoming), the spillover is -0.06 for traded goods and 0.01 for nontraded goods. We will first set those spillovers at zero and then choose some values used in the literature to check whether our results are robust under different shock structures.

Let $A_{H t}^{N}$ and $A_{H t}^{D}$ be respectively, the productivity shocks in nondurable and durable good sectors of Home country. They follow univariate $A R(1)$ processes in the benchmark model ${ }^{21}$

$$
\begin{aligned}
& A_{H t+1}^{N}=\Xi_{1} A_{H t}^{N}+\varepsilon_{H t+1}^{N} \\
& A_{H t+1}^{D}=\Xi_{2} A_{H t}^{D}+\varepsilon_{H t+1}^{D} .
\end{aligned}
$$

As in Erceg and Levin (2007), the $A R(1)$ coefficient $\Xi_{1}$ is set to 0.87 and $\Xi_{2}$ is set to 0.9 . The variancecovariance matrix of innovations $\left[\varepsilon_{H t}^{N} \varepsilon_{H t}^{D} \varepsilon_{F t}^{N} \varepsilon_{F t}^{D}\right]^{\prime}$ takes the form of

$$
\Sigma=\left[\begin{array}{cccc}
\sigma_{N}^{2} & \sigma_{D N} & \rho_{N} \times \sigma_{N}^{2} & 0 \\
\sigma_{D N} & \sigma_{D}^{2} & 0 & \rho_{D} \times \sigma_{D}^{2} \\
\rho_{N} \times \sigma_{N}^{2} & 0 & \sigma_{N}^{2} & \sigma_{D N} \\
0 & \rho_{D} \times \sigma_{D}^{2} & \sigma_{D N} & \sigma_{D}^{2}
\end{array}\right]
$$

where $\sigma_{N}^{2}$ is the variance of $\varepsilon_{H t}^{N}\left(\varepsilon_{F t}^{N}\right) . \sigma_{D}^{2}$ is the variance of $\varepsilon_{H t}^{D}\left(\varepsilon_{F t}^{D}\right)$ and $\sigma_{D N}$ is the covariance. As in Erceg and Levin (2007), the standard deviation of $\varepsilon_{H t}^{N}\left(\sigma_{N}\right)$ is 0.0096 and it is 0.036 for $\sigma_{D}$. Within each country, the innovations are correlated across sectors. The correlation $\frac{\sigma_{D N}}{\sigma_{D} \sigma_{N}}$ is set to 0.29 as in Erceg and Levin (2007). The cross-country correlation of innovations in durable good sector $\left(\rho_{D}\right)$ is 0.258 by following BKK and it is set to zero in nondurable good sector $\left(\rho_{N}=0\right.$ ). (Corsetti et. al. (forthcoming) estimate $\rho_{N}$

\footnotetext{
${ }^{20}$ Whelan (2003) calibrates this parameter to be 1 . Baxter (1996) finds that a reasonable range for this variable is between 0.5 and 2.5 .

${ }^{21}$ There is a similar structure for shocks in the Foreign country.
} 
to be zero.) This shock structure corresponds to the Benchmark model in Table 6 .

Corsetti, Dedola, and Leduc (forthcoming) find a larger $\rho_{D}$ in their estimates. In the model High Correlation of Table 6 , we change $\rho_{D}$ to their value of 0.468 . We also release the constraint of no spillovers in the following two exercises. The process of shocks is modified to a $\operatorname{VAR}(1)$ format

$$
\begin{aligned}
& A_{H t+1}^{N}=\Xi_{1} A_{H t}^{N}+\Xi_{3} A_{F t}^{N}+\varepsilon_{H t+1}^{N} \\
& A_{H t+1}^{D}=\Xi_{2} A_{H t}^{D}+\Xi_{3} A_{F t}^{D}+\varepsilon_{H t+1}^{D} \\
& A_{F t+1}^{N}=\Xi_{1} A_{F t}^{N}+\Xi_{3} A_{H t}^{N}+\varepsilon_{F t+1}^{N} \\
& A_{F t+1}^{D}=\Xi_{2} A_{F t}^{D}+\Xi_{3} A_{H t}^{D}+\varepsilon_{F t+1}^{D},
\end{aligned}
$$

where coefficient $\Xi_{3}$ is the cross-country spillover of productivity shocks. ${ }^{22}$ BKK find a relatively large spillover of 0.088 . In our first exercise, we set $\Xi_{3}$ to this value. This corresponds to the model High Spillover in Table 6. In the second exercise, we set $\Xi_{3}$ at a medium level of 0.044. Its results are reported under the model Medium Spillover in Table 6.

\section{Performance of Benchmark Model}

The model is solved and simulated using the first-order perturbation method. The model's artificial time series are logged (except for net exports) and Hodrick-Prescott (H-P) filtered with a smoothing parameter of 1600 . The reported statistics in this section are averages across 100 simulations. Our benchmark model performs well in three broad categories. First, the model can match the observed IRBC statistics, including the "trade volatility" and "positive comovement" of imports and exports as documented in Section 2.1. Second, the model can replicate the elasticity puzzle in the trade literature. Finally, our model can replicate the Backus-Smith puzzle and offers some new insights on this puzzle.

\subsection{International RBC Statistics}

Table 6 shows simulation results for four models. In the benchmark model, we assume that there is no spillover of productivity shocks across sectors and countries. But innovations in durable good sector are positively correlated across countries. In the model of High Correlation, the correlation of innovations is set to a higher level as in Corsetti, Dedola, and Leduc (forthcoming). Models High Spillover and Medium Spillover allow spillover of productivity shocks across countries. In the model High Spillover, the spillover

\footnotetext{
${ }^{22}$ As in Erceg and Levin (2007), we assume the cross-sector spillover is still zero.
} 
coefficients is set to 0.088 , which has been used by BKK. In the literature, smaller values have also been used. So in the model of Medium Spillover, we set this parameter to 0.044. All of these models can match data fairly well in the following respects:

1. The models can replicate the volatility (relative to that of GDP) of aggregate variables such as consumption, investment, durable consumption, and labor.

2. Real imports, exports and net exports are as volatile as in the data. That is, our model can successfully replicate the excessive volatility of imports and exports.

3. Both imports and exports are pro-cyclical and positively correlated with each other. Net exports are counter-cyclical.

4. The CPI-based real exchange rate is about twice as volatile as GDP.

A noticeable difference between our benchmark model and the models with cross-country correlation of technology shocks is that the volatility of imports and exports decreases when we allow spillovers. ${ }^{23}$ This result is consistent with BKK's finding that net exports become less volatile when cross-country spillovers increase. But even when we set the spillover coefficient at 0.088 , which is relatively large in the literature, imports and exports are still about two times as volatile as output. If we set the spillover coefficient to a moderate level of 0.044 , the simulation results are very close to our benchmark results.

In all of our calibrations, we note the following shortcomings: As in almost all RBC models, real exchange rate volatility is still lower than in the data. However, our model does quite well relative to the literature. The standard deviation of the real exchange rate in our benchmark model is roughly $50 \%$ of the standard deviation in the data. Across all specifications, our model produces somewhat lower correlations of real imports with GDP than appear in the data. And, perhaps as a consequence, net exports are not as negatively correlated with GDP as in the data.

Cross-country output correlation is nearly zero in the standard IRBC models, though this correlation is usually large in the data. ${ }^{24}$ Our model provides little insight on this issue. We find that the cross-country correlation of output increases if we allow innovations to be correlated across countries. For instance, if we set cross-country correlation of innovations to 0.258 for both durable good and nondurable good sectors in the model of Medium Spillover, the cross-country output correlation increases from -0.01 to 0.1. However, it is still far less than it in the data. Kose and Yi (2003) find that their model can generate stronger cross-

\footnotetext{
${ }^{23}$ The difference is more significant if we keep the adjustment costs the same across models.

${ }^{24}$ For instance, the cross-country output correlation in BKK (1992) is -0.18.
} 
country correlations for pairs of countries that trade more. But the increased correlation still falls far short of the empirical findings.

When productivity shocks are persistent, it is well understood that investment will be volatile. Agents wish to change the capital stock quickly to take advantage of current and anticipated productivity shocks. This effect contributes to the high volatility our model produces for imports and exports, because capital goods are traded. A positive productivity shock leads to a desire to increase Homes stock of domestically produced and foreign produced capital. This leads to the increase in demand for imports when there is a positive productivity shock. A positive productivity shock also increases the supply of Homes export good, lowering its world price, and thus increasing exports.

These effects are standard in RBC models, and explain why the models can generate procyclical imports and exports. However, if only investment goods are durable, and consumption goods are nondurable, the model does not produce sufficient volatility in imports and exports. For instance, if we change the depreciation rate of durable consumption $\left(\delta_{D}\right)$ to one and the adjustment cost to zero, the (relative) standard deviation of imports and exports decreases from 2.6 to $2 .{ }^{25}$ When we introduce a consumer durable sector, there is an additional source of volatility. Demand for consumer durables, like demand for investment goods, is forward looking. It is not expected productivity per se, but rather higher wealth from higher expected future income that leads to volatility in demand for durable consumer goods.

Consider the effect of a positive productivity shock in the production of durable goods. Because the shock is persistent, there is a significant wealth effect that pushes up demand for both home and foreign durable consumption goods. In addition, there is an increase in the relative price of nondurable goods, which leads to substitution from nondurables to durables. The price of home-produced durables relative to foreign-produced durables also increases, which leads to substitution toward home-produced durables. But overall, the wealth effect and the effect of the decline in the price of nondurables lead to an increase in import demand, despite the increase in the price of foreign durables relative to home durables. Indeed, total expenditure on imports increases more than the value of exports, leading to a decline in the trade balance. However, part of that increase in import expenditure comes from the increased price of imports. But overall, the model still generates procyclical movements of import and export quantities.

Figure 5 shows the correlations between US GDP and real imports, exports and net exports at various leads and lags. As noted by Ghironi and Melitz (2007), the correlation between GDP and imports exhibits a

\footnotetext{
${ }^{25}$ In this exercise, the capital adjustment cost is changed such that the (relative) standard deviation of investment is the same as in our benchmark model (2.6). We also change the elasticity of substitution between the home and foreign consumption goods to 0.9 , which reflects the fact that the short-run elasticity of substitution is low in our benchmark model due to adjustment costs.
} 
tent-shaped pattern, while the correlations of exports and net exports with GDP are S-shaped. ${ }^{26}$ Our model captures these qualitative patterns well. Note in particular that the model captures the fact that, while current imports are positively correlated with GDP, imports are negatively correlated with lagged GDP at longer horizons. However, our model's correlation of both imports and exports with lagged GDP declines quickly - too quickly - as the horizon increases. It appears especially that exports increase with a lagged response to a positive shock to GDP. It might be possible to capture this dynamic behavior by incorporating a lag between orders of durable goods and delivery.

\subsection{Elasticity Puzzle}

The elasticity of substitution between the home and foreign goods is defined as the percentage change of demand for imports relative to home goods, given a one percent change of the import price relative to the home-good price. Two methods have been used in the literature to estimate this elasticity. In the literature of trade liberalization, studies investigate how much the demand for foreign goods increases after a permanent relative price change caused by tariff reduction. In the data, the trade share of output increases substantially over time after a small but permanent decrease in the tariff. This empirical finding suggests that the home and foreign goods are highly substitutable. So the estimates from this strand of literature range from 6 to 15 with an average of 8. For instance, see Feenstra and Levinsohn (1995), Head and Ries (2001), Lai and Trefler (2002). ${ }^{27}$

In another strand of literature, the same elasticity is estimated from transitory relative price changes at the business cycle frequency. We show with a simple example in Appendix A.3 that under a general setup used in the literature, those two methods are estimating the same parameter. However, estimates from business cycle frequency data are much smaller, in a range of 0.2 to 3.5. This result is robust for both disaggregate and aggregate data. For instance, see Reinert and Roland-Holst (1992), Blonigen and Wilson (1999), and Reinert and Shiells (1993) for studies on disaggregate data, and Heathcote and Perri (2002) and Bergin(2006) for estimates from aggregate data. These findings have been labeled as the "elasticity puzzle" in the trade literature. ${ }^{28}$

Several studies have offered explanations for this puzzle with a common feature that the long-run elasticity of substitution is high, but the short-run elasticity is low due to some market frictions. ${ }^{29}$ Our model is closely

\footnotetext{
${ }^{26}$ Ghironi and Melitz (2007) have also implicitly observed the procylicality of imports and exports in their Figure 1.

${ }^{27} \mathrm{Yi}$ (2003) also points out that to replicate this empirical finding in a general equilibrium (GE) model, we need an elasticity of more than 14, which is counterfactually high. He argues that measured trade grossly overstates the value added component of exports, because many exports include a lot of imported contents due to vertical specialization. This overcounting of trade may be able to explain why a small tariff reduction leads to a large increase of trade share in the data.

${ }^{28}$ See Ruhl (2005) for more discussion on this puzzle.

${ }^{29}$ For instance, see Ruhl (2005), Drozd and Nosal (2007), and Ramanarayanan (2007).
} 
related. By the calibration of our model, the home and foreign goods are highly substitutable in the long run. The short-run frictions in our model are adjustment costs of durable consumption and capital stocks. We calibrate those costs to match the volatility of investment and durable consumption. Under these conditions, we investigate whether adjustment costs can also deliver a reasonable short-run elasticity.

To calculate the short-run elasticity of substitution, we regress the (log) relative demand on the (log) relative price. We need the following variables in our regression: demand for foreign goods, domestic demand for home goods and the relative price. The demand for foreign goods is measured by real imports $\left(R I M_{t}\right)$. The domestic demand for home goods is measured by domestic absorption $\left(D A_{t}\right)$, which is calculated by subtracting real imports from the sum of consumption and investment

$$
D A_{H t}=T C_{H t}+I_{H t}-R I M_{H t},
$$

where $T C_{H t}$ and $I_{H t}$ are total consumption and investment respectively. We define the price of domestic absorption as

$$
P_{H t}^{D A}=\left(P_{H t}^{N}\right)^{\frac{\omega_{1}}{\omega}}\left(P_{H t}^{D H}\right)^{\frac{\omega-\omega_{1}}{\omega}}
$$

where $\omega_{1}$ is the steady-state expenditure share of nondurable consumption, and $\omega$ is the share of domestic absorption in total output. So $\frac{\omega_{1}}{\omega}$ is the expenditure share of nondurable goods in domestic absorption and $\frac{\omega-\omega_{1}}{\omega}$ is the expenditure share of durable goods in total absorption.

We simulate our model and regress $\log \left(\frac{R I M_{t}}{D A_{t}}\right)$ on $\log \left(\frac{P_{I M t}}{P_{D A_{t}}}\right)$, where $P_{I M t}$ is import price. ${ }^{30}$ The estimated short-run elasticity of substitution is 1.05 with a standard error of 0.20 . In the empirical studies with disaggregate data, the average of estimates is about 0.85 . For instance, the cross-industry average in Reinert and Roland-Holst (1992) is 0.91 and it is 0.81 in Blonigen and Wilson (1999). In aggregate models, Heathcote and Perri (2002) find a point estimate of 0.9. Bergin (2006) estimates a New Open Economy Macro model and obtains an estimate of 1.13. So the short-run elasticity of substitution implied by our model is very close to what is found in the data.

It is not surprising, of course, that we are able to generate an elasticity that is lower in the short run than in the long run by introducing costs of adjustment. Our point is simply that in a model in which trade is in durables, this is natural and accords with a long tradition in macroeconomics of modeling the gradual accumulation of capital. That is, the trade elasticity puzzle is easy to understand in a context in which trade

\footnotetext{
${ }^{30} \mathrm{~A}$ constant is also added in the regression. As in empirical studies, our estimate is subject to the endogeneity problem. We do not control this problem here, because the goal of this exercise is to find whether we can replicate empirical findings instead of obtaining the true elasticity in our model.
} 
is in durables which are accumulated slowly over time.

\subsection{Backus-Smith Puzzle}

Backus and Smith (1993) show in a model with nontraded goods that the real exchange rate should be perfectly correlated with cross-country relative consumption if households can trade a full set of contingent claims. This prediction is at odds with the data: the correlation of the real exchange rate and relative consumption among OECD countries is generally negative. Corsetti, Dedola, and Leduc (forthcoming) find the median of this correlation between the US and the remaining OECD countries is -0.42 . These empirical findings are interpreted as lack of international risk sharing. ${ }^{31}$ However, Chari, Kehoe, and McGrattan (2002) show that incomplete financial markets are not sufficient: even a DSGE model with only bond markets implies a strong positive correlation. Some recent papers offer models to solve this puzzle. Corsetti, Dedola, and Leduc (forthcoming) find that if the elasticity of substitution between the home and foreign goods is small enough, the terms of trade improve, instead of deteriorate, in the face of a positive productivity shock in the home country. This could generate a negative correlation between the real exchange rate and relative consumption. Begnigo and Thoenissen (2007) show that even if the terms of trade deteriorate after a positive shock in the trade sector, the Balassa-Samuelson and wealth effects could be strong enough to generate a real appreciation in a model with nontraded goods. They argue that the price of nontraded goods increases after a positive shock in the tradable good sector, which calls for an appreciation of the real exchange rate. This effect could dominate the deterioration of the terms of trade and induce a real appreciation.

In this paper, we can also replicate the Backus-Smith empirical findings. The dynamics of consumption and the real exchange rate in response to a shock to productivity in the durable sector look very much like those in Benigno and Thoenissen (2007). A positive shock lowers the price of the durable export, and because of home bias, that tends to work toward a real CPI depreciation. But that effect can be more than offset by the increase in the price of nondurable goods, which are not traded across countries. There are two forces working to push up the price of non-traded goods: First, there is the traditional Balassa-Samuelson effect. The increase in productivity pushes up the real wage, thus pushing up the relative price of non-tradables. In addition, overall consumption in the home country increases from a wealth effect, because higher productivity increases lifetime income for the home country. Even if there were no factors mobile between sectors, that would tend to push up the price of the nontradable goods, and help foster a real appreciation. We have that aggregate consumption is increasing, and under our calibrations, a real appreciation - these correspond to the data.

\footnotetext{
${ }^{31}$ For instance see Lewis (1999), and Obstfeld and Rogoff (2001).
} 
However, our model also offers some new insight on this puzzle. The durable consumption measured in national accounts data is expenditures on new durable consumption goods. However, it is the service flow from the stock of durable consumption that enters the utility function. As emphasized by Obstfeld and Rogoff (2006, page 98), the consumer smooths the service flow from the stock of durable consumption, instead of the path of expenditures on durables. As in the data, the total consumption is measured by the sum of nondurable consumption and the investment in durable consumption

$$
T C_{H t}=C_{H t}+D C_{H t},
$$

where $T C_{H t}$ is the total consumption in Home country. $C_{H t}$ is nondurable consumption and $D C_{H t}$ is durable consumption. Durable consumption is defined as the sum of Home- and Foreign-good durable consumption

$$
D C_{H t}=\hat{P}_{H t}^{D H}\left(d_{H t}^{H}+\Delta_{H t}^{H}\right)+\hat{P}_{H t}^{D F}\left(d_{H t}^{F}+\Delta_{H t}^{F}\right)
$$

From the utility function, we know the "true" consumption (utility consumption) is

$$
U C_{H t}=\left(\mu^{\frac{1}{\zeta}} D_{H t}^{\frac{\zeta-1}{\zeta}}+(1-\mu)^{\frac{1}{\zeta}} C_{H t}^{\frac{\zeta-1}{\zeta}}\right)^{\frac{\zeta}{\zeta-1}} .
$$

We calculate the correlation of 1 . the ( $\log )$ CPI-based real exchange rate and the (log) relative total consumption $\left(\log \left(T C_{H t}\right)-\log \left(T C_{F t}\right)\right)$, and 2. the utility-based real exchange rate and the $(\log )$ relative utility consumption $\left(\log \left(U C_{H t}\right)-\log \left(U C_{F t}\right)\right) \cdot{ }^{32}$ The correlation between the real exchange rate and total consumption differential $\left(\log \left(T C_{H t}\right)-\log \left(T C_{H t}\right)\right)$ is -0.23 . So our model can replicate the negative correlation between the real exchange rate and consumption documented in the data. However, the correlation between the utility-based real exchange rate and the utility consumption differential $\left(\log \left(U C_{H t}\right)-\log \left(U C_{H t}\right)\right)$ is 0.26. Based on the fact that the financial market is limited to trade in non-state-contingent real bonds and leisure is nonseparable in the utility function, a correlation of 0.26 still implies a relatively good amount of risk sharing between the Home and Foreign countries.

It is interesting that true consumption acts more like it does in the model with complete contingent claims, though measured relative consumption and the real exchange rate are negatively correlated. We do not see an increase in utility consumption after a positive shock. In fact, it may decrease. First, consumption of services from durables cannot change, because it is predetermined by the stock of durables. While there is a positive wealth effect that would tend to increase the consumption of nondurables, this is more than

\footnotetext{
${ }^{32}$ Please see Appendix A.4 for details about how to calculate the utility-based real exchange rate.
} 
offset by the increase in their relative price. That is, the substitution effect dominates the wealth effect, and demand for nondurables falls. In Figure 4, we show impulse response functions for a one-standard-deviation shock in the durable good sector of home country. In the face of the shock, home total consumption increases relative to foreign consumption. The price of nondurable increases (or the price of durable decreases.) The consumption of nondurable goods decreases, in that the substitution effect dominates the wealth effect. ${ }^{33}$ Although the terms of trade deteriorate, the real exchange rate appreciates due to a strong increase in the price of nondurable goods.

\section{Conclusion}

The behavior of imports and exports is, of course, a key component of the linkages among economies. Our model confronts and, to a degree, successfully explains some strong empirical regularities. By modeling trade in durables, we can understand the high volatility of imports and exports relative to output. Trade in durables also offers a natural explanation for the trade elasticity puzzle - that the response of imports to changes in the terms of trade is low at business cycle frequencies, but is high when considering the long-run effect of permanent price changes. Our model performs well compared to other models, because it offers an explanation that is also consistent with the observation that imports and exports are both procyclical, and positively correlated with each other, even when the terms of trade and real exchange rate are as volatile as in the data.

We believe the forward-looking nature of investment decisions and decisions to purchase consumer durables are a key feature of trade behavior. Our model noticeably fails to account for the high correlation of output across countries, which is a failure shared by essentially all rational expectations equilibrium models. However, we think that modeling trade as durables may still be a promising avenue for dealing with this puzzle as well, through channels that are not explored in this paper. One possibility is that while the common (across countries) component of productivity shocks may account for a small share of the variance of productivity, it may be that agents typically receive strong signals about the future common component. If news helps to drive business cycles (as in Beaudry and Portier, 2005), then perhaps news about the common component of productivity shocks helps contribute to the high correlation of business cycles across countries. News about future productivity is especially important for durables, so the impact of news may be especially strong on the investment and consumer durables sectors.

Another avenue that may deserve further exploration is a model with nominal price stickiness, as in

\footnotetext{
${ }^{33}$ If the shock is very persistent, the wealth effect could dominate the substitution effect and the nondurable consumption increases.
} 
DSGE models. Our model of durable trade creates large swings in demand for imports, which indeed is what allows it to account for trade volatility. But an increase in Home demand for Foreign output has only a small effect on Foreign's output level. Instead, in our model, prices adjust so that more of Foreign's output is channeled toward Home. In a model with sticky prices, changes in demand may lead to changes in aggregate output, and so create a channel for international spillovers. While these channels do exist in current DSGE models, they are not strong because the models do not account for large procyclical movements in imports and exports.

It is an empirical fact that a large fraction of trade is in durables. Indeed, we view explaining this phenomenon - rather than assuming it, as we do in this study - to be another interesting topic for future research. What we have accomplished here is to demonstrate that trade in durables significantly alters the behavior of imports and exports in an RBC model in a way that can account for some striking empirical facts. 


\section{References}

[1] Backus, D., P. Kehoe, and F. Kydland 1992. International Real Business Cycles, Journal of Political Economy 100, 745-775.

[2] Backus, D., P. Kehoe, and F. Kydland 1994. Dynamics of the trade balance and the terms of trade: The J-curve? American Economic Review 84, 84-103.

[3] Backus, D., P. Kehoe, and F. Kydland 1995. International business cycles: Theory and evidence, in T. Cooley, ed., Frontiers of Business Cycle Research, Princeton University Press, 1995.

[4] Baxter, M. 1992. Fiscal policy, specialization, and trade in the two-sector model: The return of Ricardo? Journal of Political Economy 100(4), 713-744.

[5] Baxter, M. 1995. International trade and business cycles, in G. Grossman and K. Rogoff, eds., Handbook of International Economics 3.

[6] Baxter, M. 1996. Are Consumer Durables Important for Business Cycles? Review of Economics and Statistics 78(1), 147-155.

[7] Baxter, M. and M. Crucini 1995. Business Cycles and the Asset Structure of Foreign Trade, International Economic Review 36, 821-854.

[8] Baxter, M. and A. Stockman 1989. Business cycles and the exchange-rate regime: Some international evidence, Journal of Monetary Economics 23, 377-400.

[9] Beaudry, P. and F. Portier, 2005. When Can Changes in Expectations Cause Business Cycle Fluctuations in Neo-Classical Settings? Journal of Economic Theory, forthcoming.

[10] Benigno, G. and C. Thoenissen, 2007. Consumption and Real Exchange Rates with Incomplete Markets and Non-traded Goods, Journal of International Money and Finance forthcoming.

[11] Bergin, P. 2006. How Well Can the New Open Economy Macroeconomics Explain the Exchange Rate and Current Account? Journal of International Money and Finance 25 (5), 675-701.

[12] Bernanke, B. 1985. Adjustment Costs, Durables, and Aggregate Consumption, Journal of Monetary Economics 15, 41-58.

[13] Bertola, G., L. Guiso, and L. Pistaferri, 2005. Uncertainty and Consumer Durables Adjustment, Review of Economic Studies 72(4), 9731007. 
[14] Blonigen, B. and W. Wilson, 1999. Explaining Armington: What Determines Substitutability between Home and Foreign Goods? Candian Journal of Economics 32(1), 1-21.

[15] Boileau, M 1999. Trade in Capital Goods and the Volatility of Net Exports and the Terms of Trade, Journal of International Economics 48(2), 347-365.

[16] Chari, V., Kehoe, P. and McGrattan, E., 2002. Can Sticky Price Models Generate Volatile and Persistent Real Exchange Rates? Review of Economic Studies 69(3), 533-563.

[17] Cole, H. and M. Obstfeld 1991. Commodity Trade and International Risk Sharing: How Much Do Financial Markets Matter? Journal of Monetary Economics 28, 3-24.

[18] Corsetti, G., L. Dedola, and S. Leduc forthcoming. International Risk Sharing and the transmission of productivity shock, Review of Economic Studies, forthcoming.

[19] Drozd, L. and J. Nosal 2007. Understanding International Prices: Customers as Capital, University of Minnesota working paper.

[20] Eaton, J. and S. Kortum 2001. Trade in Capital Goods, European Economic Review 45(7), 1195-1235.

[21] Erceg, C., L. Guerrieri, and C. Gust 2006. Trade Adjustment and the Composition of Trade, International Finance Discussion Papers, Board of Governors of the Federal Reserve System.

[22] Erceg, C. and A. Levin 2007. Optimal Monetary Policy with Durable Consumption Goods, Journal of Monetary Economics 53, 1341-1359.

[23] Feenstra, R. and J. Levinsohn 1995. Estimating Markups and Market Conduct with Multidimensional Product Attributes, Review of Economics Studies 62, 19-52.

[24] Gali, J., 1993. Variability of Durable and Nondurable Consumption: Evidence for Six O.E.C.D. Countries, The Review of Economics and Statistics 75(3), 418-428.

[25] Ghironi, F. and M. Melitz 2007. Trade Flow Dynamics with Heterogeneous Firms, American Economic Review Papers and Proceedings 97(2), 356-361.

[26] Greenwood, J., Z. Hercowitz, and G. Huffman 1988. Investment, Capital Utilization and Real Business Cycle, American Economic Review 78, 402-417.

[27] Head, K. and J. Ries 2001. Increasing Returns versus National Product Differentiation as an Explanation for the Pattern of U.S.-Canada Trade, American Economic Review 91(4), 858-876. 
[28] Heathcote, J. and F. Perri 2002. Financial Autarky and International Business Cycles, Journal of Monetary Economics 49, 601-627.

[29] Kollmann, R., 2004. Welfare Effects of a Monetary Union: the Role of Trade Openness, Journal of the European Economic Association 2, 289-301.

[30] Kose, A. and K. Yi, 2003. Can the Standard International Business Cycle Model Explain the Relation between Trade and Comovement? Journal of International Economics, March, 267-295.

[31] Lai, H. and D. Trefler 2002. The Gains From Trade with Monopolistic Competition: Specification, Estimation, and Mis- Specification, NBER Working Paper No.9169.

[32] Lewis, K. 1996. What Can Explain the Apparent Lack of International Consumption Risk Sharing? Journal of Political Economy 104 (2), 267-97.

[33] Mankiw, G., 1982. Hall's Consumption Hypothesis and Durable Goods, Journal of Monetary Economics $10(3), 417-425$.

[34] Obstfeld, M. and K. Rogoff 1996. Foundations of International Macroeconomics, Cambridge, MA.: MIT Press, September 1996.

[35] Obstfeld, M. and K. Rogoff 2001. The Six Major Puzzles in International Macroeconomics: Is There a Common Cause? in Ben Bernanke and Kenneth Rogoff (eds.), NBER Macroeconomics Annual, Cambridge, MA: MIT Press.

[36] Raffo, A., 2006. Net Exports, Consumption Volatility and International Real Business Cycle Models, Federal Reserve Bank of Kansas City Working Paper 06-01.

[37] Ramanarayanan, A. 2007. International Trade Dynamics with Intermediate Inputs, University of Minnesota working paper.

[38] Reinert, K. and D. Roland-Holst 1992. Armington Elasticities for United States Manufacturing Sectors, Journal of Policy Modeling 14(5), 631-639.

[39] Reinert, K. and C. Shiells 1993. Armington Models and Terms-of-Trade Effects: Some Econometric Evidence for North America, Canadian Journal of Economics 26(2), 299-316.

[40] Ruhl, K. 2005. Solving the Elasticity Puzzle in International Economics, University of Texas-Austin working paper. 
[41] Sadka, J. and K. Yi 1996. Consumer Durables, Permanent Terms of Trade Shocks, and the Recent US Trade Deficit, Journal of International Money and Finance 15(5), 797-811.

[42] Schmitt-Grohé, S. and M. Uribe 2003. Closing Small Open Economy Models, Journal of International Economics 61, 163-185.

[43] Startz, R., 1980. The Stochastic Behavior of Durable and Non-Durable Consumption, Review of Economics and Statistics LXXI (2), 356-363.

[44] Wang, J., 2007. Home Bias, Exchange Rate Disconnect, and Optimal Exchange Rate Policy, Federal Reserve Bank of Dallas working paper 0701.

[45] Warner, A., 1994. Does World Investment Demand Determine U.S. Exports? American Economic Review 84(5), 1409-1422.

[46] Whelan, K., 2003. A Two-Sector Approach to Modeling U.S. NIPA Data, Journal of Money, Credit and Banking 35(4), 627-656.

[47] Yi, K.-M. 2003. Can Vertical Specialization Explain the Growth of World Trade? Journal of Political Economy, 111(1), 52-102.

[48] Zimmermann, C. 1999. International Business Cycles and Exchange Rates Review of International Economics 7(4), 682-698. 
Figure 1: Production Structure of Standard Models

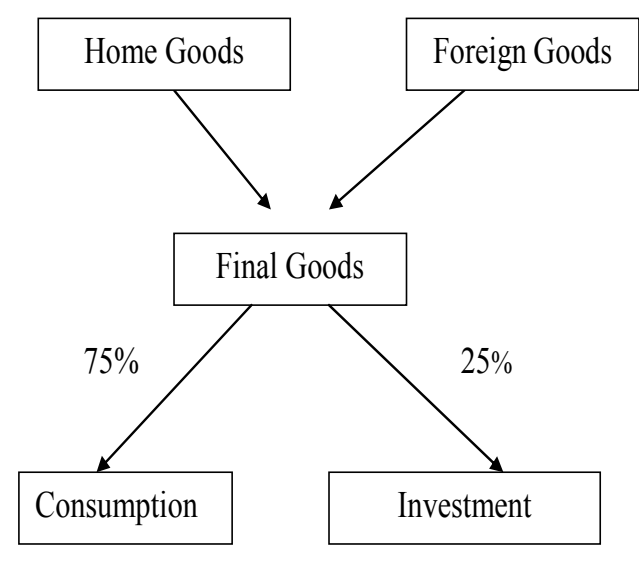

Figure 2: Structure of Benchmark Model

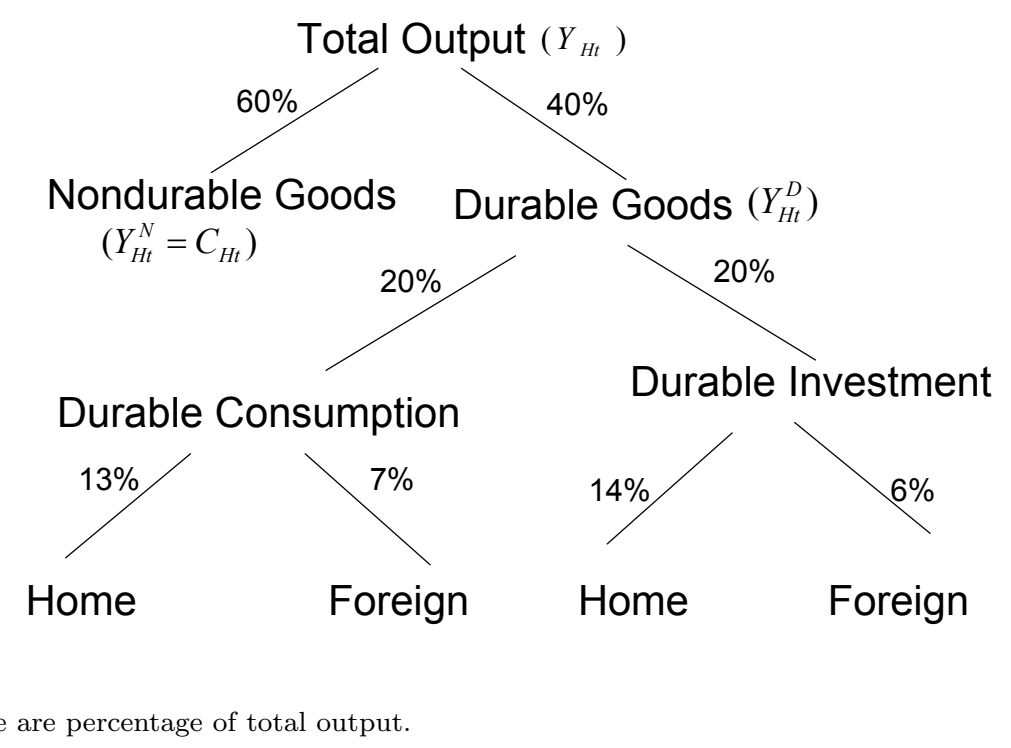


Figure 3: Share of Investment in International Trade

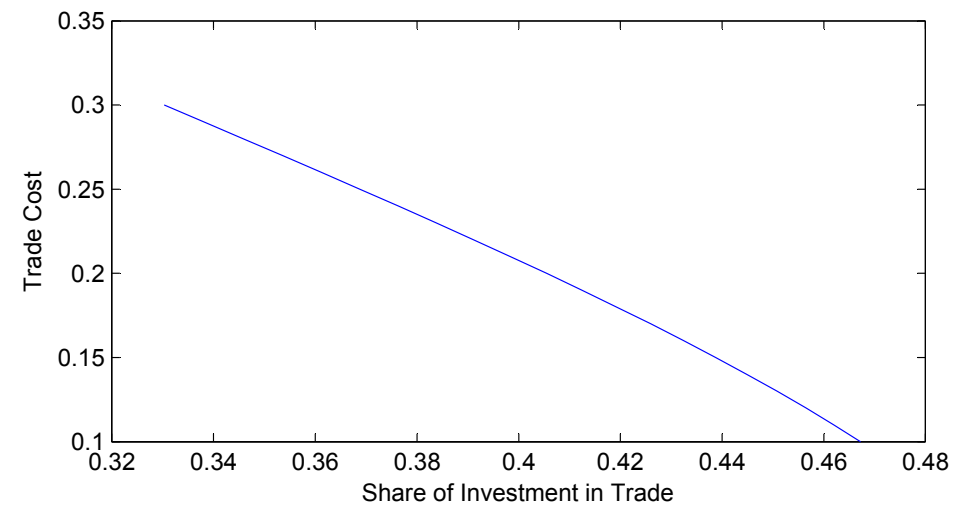

Figure 4: Impulses Response Functions
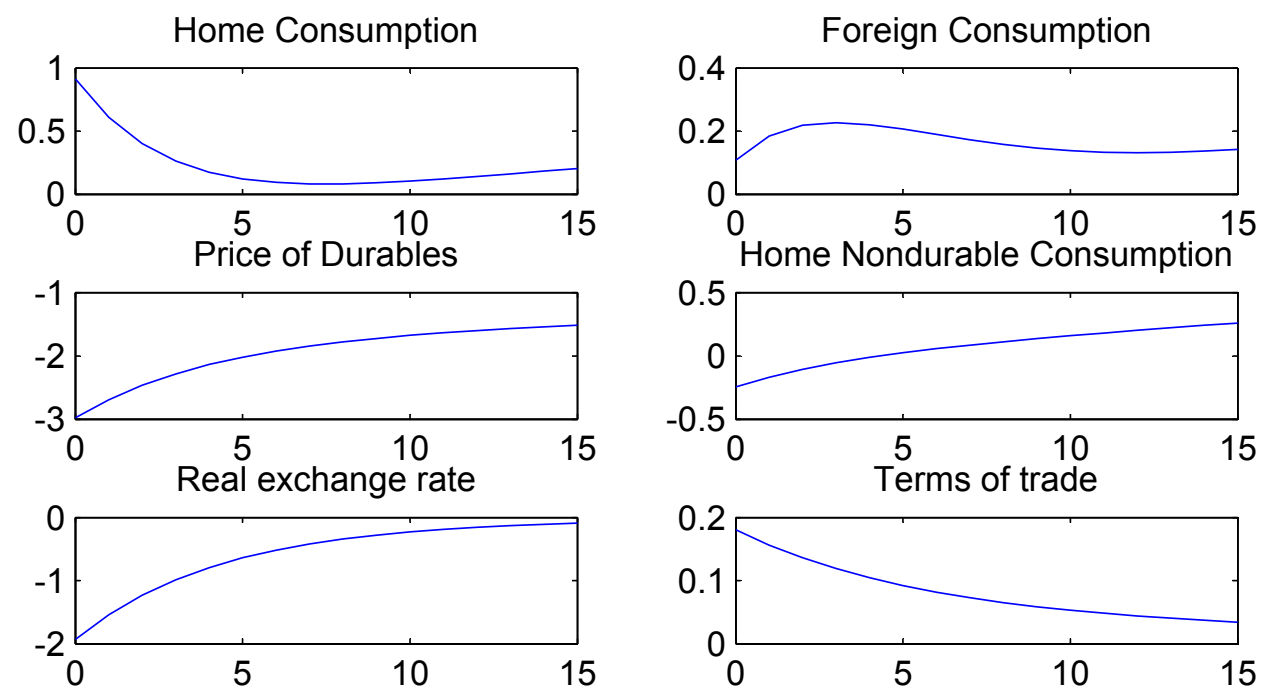

Note:

-The above figures are impulse response functions with respect to a one-standard-deviation shock in the durable good sector of home country. 
Figure 5: Cross-correlation in Different Lags
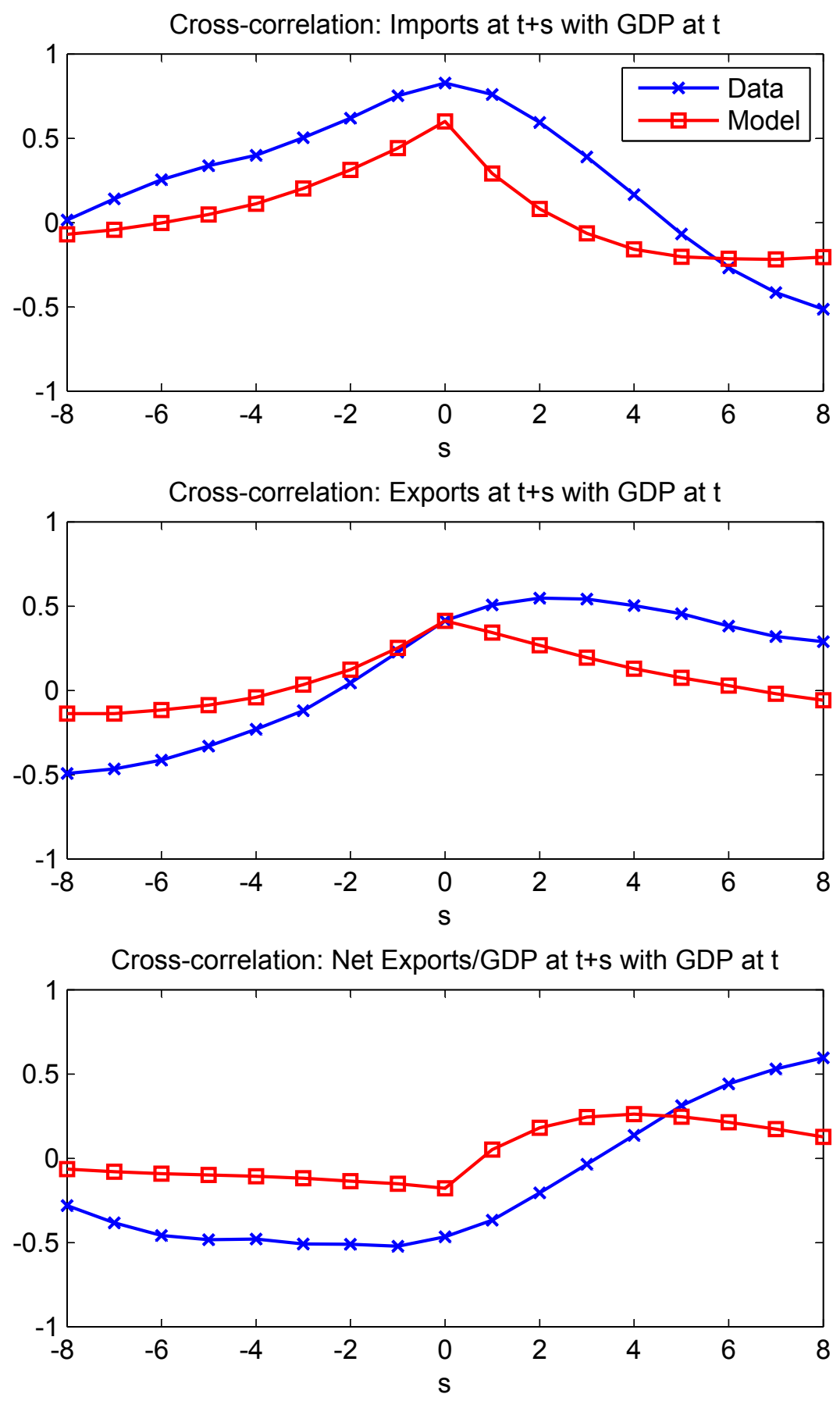

Note:

-The data are quarterly US data from OECD Economic Outlook dataset during 1973Q1-2006Q3. The model is our benchmark model. 
Table 1: Volatility of International Trade

\begin{tabular}{lcccc}
\hline \hline & & \multicolumn{3}{c}{ Standard Deviations Relative to That of GDP } \\
\cline { 3 - 5 } Country & SD of GDP $(\%)$ & Real Import & Real Export & $\frac{\text { NetExport }^{\dagger}}{\text { GDP }}$ \\
\hline Australia & 1.38 & 4.23 & 2.69 & 0.63 \\
Austria & 0.88 & 2.10 & 2.75 & 0.54 \\
Belgium & 1.03 & 2.74 & 2.36 & 0.67 \\
Canada & 1.42 & 3.15 & 2.65 & 0.66 \\
Czech Republic & 1.52 & 2.39 & 2.61 & 1.02 \\
Denmark & 1.35 & 2.65 & 2.46 & 0.72 \\
Finland & 2.02 & 2.74 & 2.73 & 0.68 \\
France & 0.86 & 3.97 & 3.22 & 0.58 \\
Germany & 1.29 & 2.26 & 2.86 & 0.69 \\
Hungary & 0.97 & 4.19 & 6.53 & 2.66 \\
Iceland & 2.18 & 3.22 & 1.91 & 1.28 \\
Ireland & 1.62 & 3.04 & 1.96 & 0.73 \\
Italy & 1.31 & 3.44 & 3.03 & 0.70 \\
Japan & 1.22 & 4.19 & 3.51 & 0.36 \\
Korea & 2.43 & 3.08 & 2.70 & 0.82 \\
Mexico & 2.36 & 5.97 & 2.53 & 0.89 \\
Netherlands & 1.28 & 2.28 & 1.99 & 0.62 \\
New Zealand & 2.58 & 2.39 & 1.53 & 0.66 \\
Norway & 1.26 & 4.01 & 3.22 & 1.37 \\
Portugal & 1.95 & 2.96 & 2.72 & 0.61 \\
Spain & 1.04 & 4.23 & 2.86 & 0.77 \\
Sweden & 1.35 & 3.14 & 2.54 & 0.70 \\
Switzerland & 1.51 & 2.78 & 2.08 & 0.54 \\
UK & 1.36 & 2.72 & 2.17 & 0.39 \\
United States & 1.52 & 3.33 & 2.63 & 0.25 \\
\hline Mean & 1.51 & 3.25 & 2.73 & 0.78 \\
Median & 1.36 & 3.08 & 2.65 & 0.68 \\
\hline \hline
\end{tabular}

Note:

-The data are from OECD Economic Outlook database. They are quarterly data of OECD 25 countries during the period between 1973Q1 and 2006Q3. (Due to data limitation, Austria starts from 1988Q1, Czech Republic starts from 1993Q1, and Hungary starts from 1991Q1.)

-The data of Germany are for West Germany only which end in 1991Q1. The data after unification (1991Q1-2006Q3) show similar patterns as reported in this table.

$\dagger-$ All variables are logged (except for $\frac{\text { NetExport }}{G D P}$ ), and HP filtered with a smoothing parameter of 1600.

-Real imports (exports) are more than twice as volatile as GDP in 22 (19) out of 25 countries at the $5 \%$ level in a one-side test. These results are obtained from 1000 bootstraps with replacement. -Similar volatility of imports and exports is also found in aggregate EU data. Results are available upon request. 
Table 2: Comovements of Interntional Trade

\begin{tabular}{lcccc}
\hline \hline & \multicolumn{3}{c}{ Correlation with GDP } & \\
\cline { 2 - 4 } Country & Real Import & Real Export & $\frac{\text { NetExport }}{\text { GDP }}$ & corr $(I M, E X)^{\ddagger}$ \\
\hline Australia & 0.49 & 0.16 & -0.33 & -0.10 \\
Austria & 0.60 & 0.67 & 0.36 & 0.85 \\
Belgium & 0.73 & 0.74 & -0.17 & 0.92 \\
Canada & 0.74 & 0.66 & -0.12 & 0.62 \\
Czech Republic & 0.53 & 0.33 & -0.09 & 0.74 \\
Denmark & 0.55 & -0.09 & -0.57 & 0.53 \\
Finland & 0.73 & 0.22 & -0.41 & 0.36 \\
France & 0.77 & 0.68 & -0.27 & 0.57 \\
Germany & 0.78 & 0.52 & -0.06 & 0.40 \\
Hungary & 0.54 & 0.53 & 0.14 & 0.25 \\
Iceland & 0.59 & 0.45 & -0.29 & 0.06 \\
Ireland & 0.38 & 0.50 & -0.08 & 0.77 \\
Italy & 0.70 & 0.38 & -0.26 & 0.38 \\
Japan & 0.60 & 0.16 & -0.34 & 0.21 \\
Korea & 0.81 & 0.31 & -0.62 & 0.28 \\
Mexico & 0.75 & -0.20 & -0.78 & -0.32 \\
Netherlands & 0.61 & 0.62 & -0.10 & 0.75 \\
New Zealand & 0.40 & 0.22 & -0.18 & -0.25 \\
Norway & 0.34 & 0.36 & -0.03 & 0.13 \\
Portugal & 0.81 & 0.51 & -0.38 & 0.44 \\
Spain & 0.56 & 0.05 & -0.46 & -0.14 \\
Sweden & 0.61 & 0.46 & -0.25 & 0.53 \\
Switzerland & 0.66 & 0.68 & -0.10 & 0.72 \\
UK & 0.61 & 0.45 & -0.25 & 0.59 \\
United States & 0.83 & 0.41 & -0.47 & 0.19 \\
\hline Mean & 0.63 & 0.39 & -0.24 & 0.38 \\
Median & 0.61 & 0.45 & -0.25 & 0.40 \\
\hline \hline & & & & \\
Note & & & & \\
\hline
\end{tabular}

Note:

-The data are from OECD Economic Outlook database. They are quarterly data of OECD 25 countries during the period between 1973Q1 and 2006Q3. (Due to data limitation, Austria starts from 1988Q1, Czech Republic starts from 1993Q1, and Hungary starts from 1991Q1.) -The data of Germany are for West Germany only which end in 1991Q1. The data after unification (1991Q1-2006Q3) show similar patterns as reported in this table.

$\dagger-$ All variables are logged (except for $\frac{\text { NetExport }}{G D P}$ ), and HP filtered with a smoothing parameter of 1600 .

$\ddagger-\operatorname{corr}(I M, E X)$ is the correlation of real imports and exports.

-Real imports (exports) are positively correlated with GDP in 25 (21) out of 25 countries at the $5 \%$ level in a one-side test. Under the same test, real net exports are negatively correlated with GDP in 15 out of 25 countries and real imports and exports are positively correlated in 19 out of 25 countries. These results are obtained from 1000 bootstraps with replacement.

-Similar cyclicality of imports and exports is also found in aggregate EU data. Results are available upon request. 
Table 3: Performance of Standard Models

\begin{tabular}{|c|c|c|c|c|c|c|}
\hline & \multicolumn{6}{|c|}{ Panel A: Standard Deviations Relative to That of Real GDP } \\
\hline & Consumption & Investment & Real Import & Real Export & $\frac{\text { RealNetExport }}{\text { RealGDP }}$ & Real $\mathrm{ER}^{\sharp}$ \\
\hline $\operatorname{Data}^{\dagger}$ & 0.798 & 2.890 & 3.335 & 2.626 & 0.250 & 2.432 \\
\hline $\mathrm{HP}^{\ddagger}$ & 0.462 & 2.663 & 0.727 & 0.608 & 0.087 & 0.385 \\
\hline DSGE $^{\ddagger}$ & 0.545 & 2.830 & 0.826 & 0.835 & 0.077 & 0.375 \\
\hline $\mathrm{GHH}^{\ddagger}$ & 0.613 & 2.697 & 0.935 & 0.947 & 0.173 & 0.284 \\
\hline Lo-elast. ${ }^{\ddagger}$ & 0.401 & 2.767 & 1.651 & 1.625 & 0.467 & 1.216 \\
\hline \multirow[t]{3}{*}{$\mathrm{UIP}^{\ddagger}$} & 0.925 & 2.875 & 3.477 & 3.466 & 1.016 & 1.458 \\
\hline & & \multicolumn{3}{|c|}{ Panel B: Correlation with Real GDP } & & \\
\hline & & Real Import & Real Export & $\frac{\text { RealNetExport }}{\text { RealGDP }}$ & \multicolumn{2}{|c|}{$\operatorname{corr}\left(R I M_{t}, R E X_{t}\right)^{\sharp}$} \\
\hline $\operatorname{Data}^{\dagger}$ & & 0.827 & 0.415 & -0.467 & \multicolumn{2}{|c|}{0.194} \\
\hline $\mathrm{HP}^{\ddagger}$ & & 0.929 & 0.588 & -0.551 & \multicolumn{2}{|c|}{0.628} \\
\hline DSGE $^{\ddagger}$ & & 0.801 & 0.663 & -0.214 & \multicolumn{2}{|c|}{0.809} \\
\hline $\mathrm{GHH}^{\ddagger}$ & & 0.894 & 0.278 & -0.497 & \multicolumn{2}{|c|}{0.252} \\
\hline Lo-elast. $\ddagger$ & & -0.647 & 0.973 & 0.852 & \multicolumn{2}{|c|}{-0.799} \\
\hline \multirow[t]{3}{*}{$\mathrm{UIP}^{\ddagger}$} & & 0.286 & 0.069 & -0.112 & \multicolumn{2}{|c|}{-0.894} \\
\hline & & \multicolumn{3}{|c|}{ Panel C: Correlation with Real GDP } & \multirow{2}{*}{\multicolumn{2}{|c|}{$\operatorname{corr}\left(R I M_{t}, R E X_{t}\right)^{\sharp}$}} \\
\hline & & Real Import & Real Export & $\frac{\text { RealNetExport }}{\text { RealGDP }}$ & & \\
\hline $\mathrm{HP}^{\ddagger}$ & & 0.999 & 0.500 & -0.819 & \multicolumn{2}{|c|}{0.491} \\
\hline DSGE $\ddagger$ & & 0.988 & 0.601 & -0.552 & \multicolumn{2}{|c|}{0.634} \\
\hline $\mathrm{GHH}^{\ddagger}$ & & 0.985 & 0.241 & -0.608 & \multicolumn{2}{|c|}{0.152} \\
\hline Lo-elast. $\ddagger$ & & 0.369 & 0.984 & 0.848 & \multicolumn{2}{|c|}{0.212} \\
\hline $\mathrm{UIP}^{\ddagger}$ & & 0.569 & 0.070 & -0.181 & \multicolumn{2}{|c|}{-0.749} \\
\hline
\end{tabular}

Note:

$\sharp$-Real ER is the (CPI-based) real exchange rate. $\operatorname{corr}\left(R I M_{t}, R E X_{t}\right)$ is the correlation of real imports and exports. In Panels $\mathrm{A}$ and $\mathrm{B}$, the imports, exports and net exports are measured in constant (steady-state) prices. They are measured in Panel $\mathrm{C}$ in terms of final consumption goods.

†-US data as in Table 1 and 2.

¥-HP (Heathcote and Perri (2002)) is the standard IRBC model with incomplete financial market (real bonds only). DSGE is the standard DSGE model as described in the appendix. GHH is the DSGE model with GHH utility function. Lo-elast is the DSGE model with low intertemporal elasticity of substitution $(\sigma=5)$, and UIP is the DSGE model with the uncovered interest rate parity shock.

$\S_{-}$Statistics are based on logged (except for $\frac{\text { RealNetExport }}{\text { RealGDP }}$ ) and H-P filtered data. Entries are averages over 100 simulations of length 120 . 
Table 4: Share of Durable Goods in Trade

\begin{tabular}{lcc|cc}
\hline \hline & \multicolumn{2}{c|}{ All Imports and Exports } & \multicolumn{2}{|c}{ Exclude Materials and Energy } \\
\hline Country & Import & Export & Import & Export \\
\hline Australia & 0.64 & 0.25 & 0.71 & 0.45 \\
Austria & 0.64 & 0.65 & 0.70 & 0.69 \\
Belgium & 0.58 & 0.61 & 0.67 & 0.66 \\
Canada & 0.71 & 0.55 & 0.77 & 0.69 \\
Czech Rep & 0.64 & 0.72 & 0.73 & 0.77 \\
Denmark & 0.56 & 0.43 & 0.61 & 0.48 \\
Finland & 0.59 & 0.59 & 0.73 & 0.65 \\
France & 0.59 & 0.65 & 0.68 & 0.68 \\
Germany & 0.61 & 0.69 & 0.70 & 0.71 \\
Hungary & 0.70 & 0.75 & 0.75 & 0.78 \\
Iceland & 0.51 & 0.28 & 0.56 & 0.28 \\
Ireland & 0.69 & 0.58 & 0.73 & 0.59 \\
Italy & 0.54 & 0.62 & 0.66 & 0.64 \\
Japan & 0.42 & 0.88 & 0.58 & 0.89 \\
Korea & 0.54 & 0.73 & 0.77 & 0.78 \\
Mexico & 0.70 & 0.69 & 0.74 & 0.78 \\
Netherland & 0.59 & 0.51 & 0.69 & 0.61 \\
New Zealand & 0.58 & 0.22 & 0.66 & 0.26 \\
Norway & 0.64 & 0.21 & 0.71 & 0.61 \\
Portugal & 0.58 & 0.51 & 0.66 & 0.54 \\
Spain & 0.58 & 0.62 & 0.69 & 0.66 \\
Sweden & 0.61 & 0.69 & 0.69 & 0.76 \\
Switzerland & 0.62 & 0.67 & 0.66 & 0.69 \\
UK & 0.65 & 0.66 & 0.70 & 0.74 \\
US & 0.61 & 0.73 & 0.70 & 0.67 \\
\hline Mean & 0.60 & 0.58 & 0.69 & 0.70 \\
Median & 0.61 & 0.62 & & 0.65 \\
\hline \hline
\end{tabular}

Note:

-Data are from International Trade Data, NBER-United Nations World Trade Data (http://cid.econ.ucdavis.edu).

-Entries are shares of durable goods in imports and exports (year 2000). Left panel of the table reports results for all imports and exports. Raw materials (SITC 2) and energy products (SITC 3) are excluded from imports and exports in the right panel. 
Table 5: Calibration

\begin{tabular}{lcl}
\hline \hline Parameter & Value & Description \\
\hline$\alpha$ & 0.5 & Share of Home Goods in Capital When Trade Cost Is Zero \\
$\chi=\epsilon$ & 0.36 & Capital Share in Production \\
$\gamma$ & 9.1 & (Long-run) Elasticity of Substitution between Home and Foreign Capital \\
$\tau$ & 0.1 & (Iceberg) International Trade Cost \\
$\beta$ & 0.99 & Subjective Discount Factor \\
\hline$\delta$ & 0.013 & Depreciation Rate of Capital \\
$\delta_{D}$ & 0.05 & Depreciation Rate of Durable Consumption \\
$\mu$ & 0.23 & Share of Durable Consumption Stock in Consumption Bundle \\
$\nu$ & 1.65 & Preference Parameter of Labor Supply \\
$\psi$ & 0.5 & Share of Home Goods in Durable Consumption When Trade Cost Is Zero \\
\hline$\rho$ & 5.83 & Preference Parameter \\
$\sigma$ & 2 & Preference Parameter \\
$\theta$ & 6.85 & (Long-run) Elasticity of Substitution b/t Home and Foreign Durable Consumption \\
$\zeta$ & 1.1 & Elasticity of Substitution b/t Durable and Nondurable Consumption \\
$\phi_{1}$ & $1.4^{\dagger}$ & Durable Consumption Adjustment Cost \\
$\phi_{2}$ & $8.5^{\dagger}$ & Capital Adjustment Cost \\
\hline$\Phi$ & 0.00001 & Bond Holding Cost \\
$\Xi_{1}$ & 0.87 & AR(1) Coefficient of Technology Shock in Nondurable Good Sector \\
$\Xi_{2}$ & 0.9 & AR(1) Coefficient of Technology Shock in Durable Good Sector \\
$\sigma\left(\varepsilon_{H t}^{N}\right)$ & 0.0096 & Standard Deviation of Productivity Shock in Nondurable Good Sector \\
$\sigma\left(\varepsilon_{H t}^{D}\right)$ & 0.036 & Standard Deviation of Productivity Shock in Durable Good Sector \\
\hline \hline
\end{tabular}

Note:

$\dagger$-Entries are values used in the benchmark model. In other models, they are adjusted to match the volatility of durable consumption and aggregate investment. 
Table 6: Simulation Results of Benchmark Model

\begin{tabular}{|c|c|c|c|c|c|c|c|c|}
\hline & \multicolumn{8}{|c|}{ Panel A: Standard Deviations Relative to That of Real GDP } \\
\hline & $\mathrm{C}$ & $\mathrm{I}$ & $\mathrm{DC}$ & $\mathrm{L}$ & RIM & REX & RNX & Q \\
\hline Data $^{\dagger}$ & 0.798 & 2.890 & 2.983 & 0.670 & 3.335 & 2.626 & 0.250 & 2.432 \\
\hline Benchmark $^{\ddagger}$ & 0.878 & 2.594 & 2.473 & 0.547 & 2.633 & 2.678 & 0.337 & 1.262 \\
\hline High Correlation ${ }^{\ddagger}$ & 0.920 & 2.750 & 2.680 & 0.549 & 2.880 & 2.936 & 0.402 & 1.058 \\
\hline High Spillover ${ }^{\ddagger}$ & 0.948 & 2.905 & 2.738 & 0.539 & 1.826 & 1.775 & 0.322 & 1.297 \\
\hline \multirow[t]{3}{*}{ Medium Spillover ${ }^{\ddagger}$} & 0.917 & 2.894 & 2.754 & 0.549 & 2.652 & 2.615 & 0.393 & 1.271 \\
\hline & Correl & tion wi & GDP & & & & & \\
\hline & RIM & REX & RNX & \multicolumn{3}{|c|}{$\operatorname{corr}(R I M, R E X)$} & $\sigma_{Y, Y^{*}}$ & $\sigma_{C, C^{*}}$ \\
\hline $\operatorname{Data}^{\dagger}$ & 0.827 & 0.415 & -0.467 & \multicolumn{3}{|c|}{0.194} & 0.68 & 0.60 \\
\hline Benchmark $^{\ddagger}$ & 0.606 & 0.411 & -0.187 & \multicolumn{3}{|c|}{0.421} & 0.01 & -0.17 \\
\hline High Correlation ${ }^{\ddagger}$ & 0.630 & 0.337 & -0.288 & \multicolumn{3}{|c|}{0.265} & 0.03 & -0.20 \\
\hline High Spillover & 0.576 & 0.405 & -0.129 & \multicolumn{3}{|c|}{0.160} & -0.03 & 0.23 \\
\hline Medium Spillover & 0.599 & 0.324 & -0.228 & \multicolumn{3}{|c|}{0.171} & -0.01 & -0.14 \\
\hline
\end{tabular}

Note:

C-consumption, I-investment, DC-durable consumption, L-labor, RIM-real imports, REXreal exports, RNX-real net exports defined as $\frac{\text { RealNet Export }}{\text { RealGDP }}$, Q-CPI-based real exchange rate.

$\operatorname{corr}(R I M, R E X)$-correlation of real imports and exports, $\sigma_{Y, Y^{*}-\text { cross-country correlation of }}$

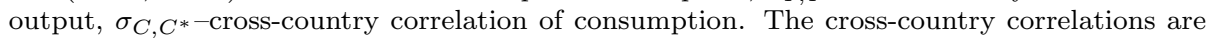
between the United States and the rest of OECD countries (Corsetti et. al. forthcoming).

†-US data as in Tables 1 and 2.

$\ddagger$-The standard deviation of GDP in benchmark model is $2.26 \%$. All variables are logged (except for RNX) and H-P filtered with a smoothing parameter of 1600 . Entries are averages over 100 simulations of length 120 . 


\section{APPENDIX}

\section{A.1 Standard Models}

In this section, we describe the standard models that we used in Section 2.2.

\section{A.1.1 IRBC Model}

The standard IRBC model is the bond-economy model in Heathcote and Perri (2002). There are two symmetric countries, Home and Foreign. In each country, there are two sectors, the intermediate and final good sectors. Because of the symmetry, we focus on the Home country in describing the model. Intermediate goods are produced from capital and labor with the standard Cobb-Douglas technology

$$
Y_{H t}^{H}+Y_{F t}^{H}=A_{H t} K_{H t}^{\theta} L_{H t}^{1-\theta},
$$

where $Y_{H t}^{H}$ is the Home intermediate goods used in the Home country and $Y_{F t}^{H}$ is the Home intermediate goods used in the Foreign country. $A_{H t}$ is the TFP shock, $K_{H t}$ is capital and $L_{H t}$ is labor supply. Capital follows the standard law of motion

$$
K_{H t+1}=(1-\delta) K_{H t}+I_{H t} .
$$

Final goods are produced from the Home and Foreign intermediate goods

$$
Y_{H t}=\left[\alpha^{\frac{1}{\gamma}}\left(Y_{H t}^{H}\right)^{\frac{\gamma-1}{\gamma}}+(1-\alpha)^{\frac{1}{\gamma}}\left(Y_{H t}^{F}\right)^{\frac{\gamma-1}{\gamma}}\right]^{\frac{\gamma}{\gamma-1}}
$$

All prices and wage are flexible. The representative household maximizes expected lifetime utility given those prices

$$
E_{t} \sum_{j=0}^{\infty} \beta^{j} u_{H t},
$$

where the period utility function $u_{H t}$ takes the form of

$$
u_{H t}=\frac{1}{1-\sigma}\left[C_{H t}^{\mu}\left(1-L_{H t}\right)^{1-\mu}\right]^{1-\sigma} .
$$

The Home and Foreign country can trade real bonds in terms of the Home country's intermediate goods. To make the model stationary, we assume a small bond holding cost as in Heathcote and Perri (2002). We 
calibrate the model with the same parameter values as in Heathcote and Perri (2002). Our simulation results are very close to those reported in their paper.

\section{A.1.2 DSGE Model}

It is a two-country symmetric model. We will focus on the Home country in describing our model. There is a continuum of differentiated intermediate goods indexed by $i \in[0,1]$. The Home intermediate good $i$ $\left(Y_{H}(i)\right)$ is produced by a single firm with capital $K_{t}(i)$ and labor $L_{t}(i)$ in the Home country. Capital and labor are not internationally mobile. Intermediate goods are aggregated into an intermediate good composite according to a standard CES function

$$
Y_{H t}=\left[\int_{0}^{1} Y_{H t}^{\frac{\phi-1}{\phi}}(i) d i\right]^{\frac{\phi}{\phi-1}}
$$

The intermediate-good market is monopolistic competitive. The firms choose prices to maximize expected profit. We follow Calvo staggered price setting in this sticky-price model. In each period, the firm has a probability of $1-\lambda$ to change its price. When $\lambda=0$, the model reduces to the flexible price setup.

Final goods are produced from the Home and Foreign intermediate good composites according to a CES function

$$
Y_{t}=\left[\alpha^{\frac{1}{\gamma}} Y_{H t}^{\frac{\gamma-1}{\gamma}}+(1-\alpha)^{\frac{1}{\gamma}} Y_{F t}^{\frac{\gamma-1}{\gamma}}\right]^{\frac{\gamma}{\gamma-1}}
$$

where $\alpha$ is the percentage of Home goods in final goods, and $\gamma$ is the elasticity of substitution between Home and Foreign goods. The final good market is competitive with flexible prices.

The household chooses sequences of consumption $C_{t}$, capital accumulation $I_{t}$, labor supply $L_{t}$, Home and Foreign nominal bonds $\left(B_{H t+1}\right.$ and $\left.B_{F t+1}\right)$ to maximize the expected lifetime utility

$$
E_{0}\left[\sum_{t=0}^{\infty} \beta^{t} u_{t}\left(C_{t}, 1-L_{t}\right)\right],
$$


where $u_{t}=\frac{\left[C_{t}^{\mu}\left(1-L_{t}\right)^{1-\mu}\right]^{1-\sigma}}{1-\sigma}$, subject to the budget constraint

$$
\begin{aligned}
C_{t} & +\frac{B_{H t+1}}{\left(1+i_{t}\right) P_{t}}+\frac{S_{t} B_{F t+1}}{\left(1+i_{t}^{*}\right) P_{t}}+I_{t}+\frac{1}{2} \Phi\left(\frac{I_{t}}{K_{t}}-\delta\right)^{2} K_{t} \\
& +\frac{1}{2} \phi_{d}\left(\frac{B_{H t+1}}{P_{t}}\right)^{2}+\frac{1}{2} \phi_{f}\left(\frac{S_{t} B_{F t+1}}{P_{t}}\right)^{2} \\
& \leq \frac{W_{t} L_{t}}{P_{t}}+\frac{R_{t} K_{t}}{P_{t}}+\frac{B_{H t}}{P_{t}}+\frac{B_{F t} S_{t}}{P_{t}}+\frac{\Pi_{t}}{P_{t}},
\end{aligned}
$$

where $\frac{1}{2} \Phi\left(\frac{I_{t}}{K_{t}}-\delta\right)^{2} K_{t}$ is capital adjustment cost, $\frac{1}{2} \phi_{d}\left(\frac{B_{H t+1}}{P_{t}}\right)^{2}$ and $\frac{1}{2} \phi_{f}\left(\frac{S_{t} B_{F t+1}}{P_{t}}\right)^{2}$ are bond holding costs for the Home and Foreign nominal bonds. $\Pi_{t}$ is the profit of intermediate-good firms. The nominal interest rate follows the Taylor rule

$$
i_{t}=i+\Xi_{\pi} \log \left(\pi_{t} / \pi\right)+\Xi_{y} \log \left(g d p_{t} / g d p\right),
$$

where $\pi_{t}$ is the inflation rate at time t.

The first order conditions of the household approximately imply uncovered interest rate parity. In the UIP model, we break this condition with uncovered interest rate parity shock by following Kollmann (2004). The values that we use to calibrate the DSGE model are listed in Table 7. Those parameter values are standard in the literature.

Table 7: Calibration of DSGE Model

\begin{tabular}{lcl}
\hline \hline Parameter & Value & Description \\
\hline \multicolumn{2}{l}{ Intermediate Goods Sector } \\
$\psi$ & 0.36 & Capital Share in Production \\
$\phi$ & 6 & Elasticity of Substitution between Differentiated Tradable Goods \\
$\lambda$ & 0.75 & Probability of Not Changing Price. \\
$\delta$ & 0.025 & Depreciation Rate of Capital \\
\hline \multicolumn{2}{c}{ Final Goods Sector } \\
$\alpha$ & 0.85 & Share of Home Goods in Final Good \\
$\gamma$ & 1.5 & Elasticity of Substitution between Home and Foreign Goods \\
\hline Household & & \\
$\beta$ & 0.99 & Subjective Discount Factor \\
$\Phi$ & 3.2 & Investment Adjustment Cost \\
$\phi_{d}$ & 0.0001 & Domestic Bond Holding Cost \\
$\phi_{f}$ & 0.0003 & Foreign Bond Holding Cost \\
$\sigma$ & 2 & Preference Parameter \\
$\mu$ & 0.36 & Preference Parameter \\
\hline Exogenous Shocks & \\
$\xi_{11}=\xi_{22}$ & 0.906 & Technology shock AR(1) coefficient \\
$\xi_{12}=\xi_{21}$ & 0.088 & Technology spillovers \\
$\sigma_{\varepsilon}$ & 0.0085 & Standard Deviation of Productivity Shock \\
\hline \hline
\end{tabular}




\section{A.2 Benchmark Model}

In this section, we give more details about our benchmark model in Section 3. We first list equations that define the equilibrium of the model, then solve for its nonstochastic steady state.

\section{A.2.1 Equilibrium Conditions}

We divide all prices by the price of nondurable consumption goods $\left(P_{H t}^{N}\right.$ in the Home country and $P_{F t}^{N}$ in the Foreign). That is, we use the nondurable consumption good as numeraire. We use a hat above all prices to denote that they are relative prices in terms of nondurable consumption. The equilibrium of the benchmark model is defined by the following equations.

\section{Nondurable Good Sector}

$$
1=\left(A_{H t}^{N}\right)^{-1}\left(\hat{R}_{H t}^{N}\right)^{\chi} \hat{W}_{H t}^{1-\chi} \chi^{-\chi}(1-\chi)^{\chi-1}
$$

where $\hat{R}_{H t}^{N}$ is defined as

$$
\begin{gathered}
\hat{R}_{H t}^{N}=\left[\alpha\left(\hat{R}_{H t}^{N H}\right)^{1-\gamma}+(1-\alpha)\left(\hat{R}_{H t}^{N F}\right)^{1-\gamma}\right]^{\frac{1}{1-\gamma}} . \\
K_{H t}^{N H}=\alpha\left(\frac{\hat{R}_{H t}^{N H}}{\hat{R}_{H t}^{N}}\right)^{-\gamma} K_{H t}^{N} \\
K_{H t}^{N F}=(1-\alpha)\left(\frac{\hat{R}_{H t}^{N F}}{\hat{R}_{H t}^{N}}\right)^{-\gamma} K_{H t}^{N} \\
K_{H t}^{N}=\chi Y_{H t}^{N} / \hat{R}_{H t}^{N} \\
L_{H t}^{N}=(1-\chi) Y_{H t}^{N} / \hat{W}_{H t}
\end{gathered}
$$

Symmetric conditions hold in the Foreign country

$$
1=\left(A_{F t}^{N}\right)^{-1}\left(\hat{R}_{F t}^{N}\right)^{\chi} \hat{W}_{F t}^{1-\chi} \chi^{-\chi}(1-\chi)^{\chi-1}
$$

where $\hat{R}_{F t}^{N}$ is defined as

$$
\hat{R}_{F t}^{N}=\left[\alpha\left(\hat{R}_{F t}^{N F}\right)^{1-\gamma}+(1-\alpha)\left(\hat{R}_{F t}^{N H}\right)^{1-\gamma}\right]^{\frac{1}{1-\gamma}} .
$$




$$
\begin{aligned}
& K_{F t}^{N F}=\alpha\left(\frac{\hat{R}_{F t}^{N F}}{\hat{R}_{F t}^{N}}\right)^{-\gamma} K_{F t}^{N} \\
& K_{F t}^{N H}=(1-\alpha)\left(\frac{\hat{R}_{F t}^{N H}}{\hat{R}_{F t}^{N}}\right)^{-\gamma} K_{F t}^{N} \\
& K_{F t}^{N}=\chi Y_{F t}^{N} / \hat{R}_{F t}^{N} \\
& L_{F t}^{N}=(1-\chi) Y_{F t}^{N} / \hat{W}_{F t}
\end{aligned}
$$

\section{Durable Good Sector}

$$
\hat{P}_{H t}^{D H}=\left(A_{H t}^{D}\right)^{-1}\left(\hat{R}_{H t}^{D}\right)^{\epsilon} \hat{W}_{H t}^{1-\epsilon} \epsilon^{-\epsilon}(1-\epsilon)^{\epsilon-1},
$$

where $\hat{R}_{H t}^{D}$ is defined as

$$
\begin{gathered}
\hat{R}_{H t}^{D}=\left[\alpha\left(\hat{R}_{H t}^{D H}\right)^{1-\gamma}+(1-\alpha)\left(\hat{R}_{H t}^{D F}\right)^{1-\gamma}\right]^{\frac{1}{1-\gamma}} . \\
K_{H t}^{D H}=\alpha\left(\frac{\hat{R}_{H t}^{D H}}{\hat{R}_{H t}^{D}}\right)^{-\gamma} K_{H t}^{D} \\
K_{H t}^{D F}=(1-\alpha)\left(\frac{\hat{R}_{H t}^{D F}}{\hat{R}_{H t}^{D}}\right)^{-\gamma} K_{H t}^{D} \\
K_{H t}^{D}=\epsilon \hat{P}_{H t}^{D H} Y_{H t}^{D} / \hat{R}_{H t}^{D} \\
L_{H t}^{D}=(1-\epsilon) \hat{P}_{H t}^{D H} Y_{H t}^{D} / \hat{W}_{H t}
\end{gathered}
$$

Symmetric conditions hold in the Foreign country.

$$
\hat{P}_{F t}^{D F}=\left(A_{F t}^{D}\right)^{-1}\left(\hat{R}_{F t}^{D}\right)^{\epsilon} \hat{W}_{F t}^{1-\epsilon} \epsilon^{-\epsilon}(1-\epsilon)^{\epsilon-1},
$$

where $\hat{R}_{F t}^{D}$ is defined as

$$
\hat{R}_{F t}^{D}=\left[\alpha\left(\hat{R}_{F t}^{D F}\right)^{1-\gamma}+(1-\alpha)\left(\hat{R}_{F t}^{D H}\right)^{1-\gamma}\right]^{\frac{1}{1-\gamma}} .
$$




$$
\begin{aligned}
& K_{F t}^{D F}=\alpha\left(\frac{\hat{R}_{F t}^{D F}}{\hat{R}_{F t}^{D}}\right)^{-\gamma} K_{F t}^{D} \\
& K_{F t}^{D H}=(1-\alpha)\left(\frac{\hat{R}_{F t}^{D H}}{\hat{R}_{F t}^{D}}\right)^{-\gamma} K_{F t}^{D} \\
& K_{F t}^{D}=\epsilon \hat{P}_{F t}^{D F} Y_{F t}^{D} / \hat{R}_{F t}^{D} \\
& L_{F t}^{D}=(1-\epsilon) \hat{P}_{F t}^{D F} Y_{F t}^{D} / \hat{W}_{F t}
\end{aligned}
$$

\section{$\underline{\text { Households }}$}

The law of motion for durable consumption

$$
\begin{aligned}
& D_{H t+1}^{H}=\left(1-\delta_{D}\right) D_{H t}^{H}+d_{H t}^{H} \\
& D_{H t+1}^{F}=\left(1-\delta_{D}\right) D_{H t}^{F}+d_{H t}^{F} .
\end{aligned}
$$

The law of motion for capital

$$
\begin{aligned}
& K_{H t+1}^{N H}=(1-\delta) K_{H t}^{N H}+I_{H t}^{N H} \\
& K_{H t+1}^{N F}=(1-\delta) K_{H t}^{N F}+I_{H t}^{N F} \\
& K_{H t+1}^{D H}=(1-\delta) K_{H t}^{D H}+I_{H t}^{D H} \\
& K_{H t+1}^{D F}=(1-\delta) K_{H t}^{D F}+I_{H t}^{D F} .
\end{aligned}
$$

The budget constraint

$$
\begin{aligned}
C_{H t}+ & \hat{P}_{H t}^{D H}\left(d_{H t}^{H}+\Delta_{H t}^{H}+I_{H t}^{N H}+\Lambda_{H t}^{N H}+I_{H t}^{D H}+\Lambda_{H t}^{D H}\right) \\
& +\frac{Q_{t} \hat{P}_{F t}^{D F} \hat{P}_{H t}}{\hat{P}_{F t}(1-\tau)}\left(d_{H t}^{F}+\Delta_{H t}^{F}+I_{H t}^{N F}+\Lambda_{H t}^{N F}+I_{H t}^{D F}+\Lambda_{H t}^{D F}+\frac{B_{H t+1}}{1+i_{t}}+\frac{1}{2} \Phi B_{H t+1}^{2}\right) \\
& \leq \hat{W}_{H t} L_{H t}+\hat{P}_{H t}^{D H} B_{H t}+\hat{R}_{H t}^{N H} K_{H t}^{N H}+\hat{R}_{H t}^{N F} K_{H t}^{N F}+\hat{R}_{H t}^{D H} K_{H t}^{D H}+\hat{R}_{H t}^{D F} K_{H t}^{D F},
\end{aligned}
$$

where $Q_{t}$ is the CPI real exchange rate. The consumer price index (CPI) is defined as

$$
\hat{P}_{H t}=\left(\hat{P}_{H t}^{D H}\right)^{\omega_{2}}\left(\frac{Q_{t} \hat{P}_{F t}^{D F} \hat{P}_{H t}}{\hat{P}_{F t}(1-\tau)}\right)^{1-\omega_{1}-\omega_{2}}
$$

where $\omega_{1}$ is the expenditure share of nondurable consumption. $\omega_{2}$ and $\omega_{3}$ are the expenditure shares of Home and Foreign durable consumption respectively. 
The followings are the first order conditions from the household's lifetime utility maximization problem.

$$
\hat{P}_{H t}^{D H}\left(1+\frac{\partial \Delta_{H t}^{H}}{\partial d_{H t}^{H}}\right)=E_{t}\left[\beta \frac{\partial u_{t+1} / \partial D_{H t+1}^{H}}{\partial u_{t} / \partial C_{H t}}-\Gamma_{t, t+1} \hat{P}_{H t+1}^{D H}\left(\frac{\partial \Delta_{H t+1}^{H}}{\partial D_{H t+1}^{H}}-\left(1-\delta_{D}\right)\left(1+\frac{\partial \Delta_{H t+1}^{H}}{\partial d_{H t+1}^{H}}\right)\right)\right]
$$

where $\Gamma_{t, t+1}=\beta \frac{\partial u_{t+1} / \partial C_{H t+1}}{\partial u_{t} / \partial C_{H t}}$ is the intertemporal elasticity of substitution of nondurable consumption goods. The left hand side of the equation is the cost in terms of nondurable goods, of increasing one unit durable consumption. The right hand side is the benefit, which includes three parts: 1 . the increase of period $t+1$ utility due to the increase of durable consumption stock $\left(\beta \frac{\partial u_{t+1} / \partial D_{H t+1}^{H}}{\partial u_{t} / \partial C_{H t}}\right) ; 2$. the adjustment cost associated with the increased consumption stock $\left(\Gamma_{t, t+1} \hat{P}_{H t+1}^{D H} \frac{\partial \Delta_{H t+1}^{H}}{\partial D_{H t+1}^{H}}\right) ;^{34} 3$. the value of undepreciated durable consumption goods $\Gamma_{t, t+1} \hat{P}_{H t+1}^{D H}\left(1-\delta_{D}\right)\left(1+\frac{\partial \Delta_{H t+1}^{H}}{\partial d_{H t+1}^{H}}\right)$. In equilibrium, the marginal cost of increasing durable consumption stock is equal to its marginal benefit.

$$
\begin{aligned}
& \frac{Q_{t} \hat{P}_{F t}^{D F} \hat{P}_{H t}}{\hat{P}_{F t}(1-\tau)}\left(1+\frac{\partial \Delta_{H t}^{F}}{\partial d_{H t}^{F}}\right) \\
& =E_{t}\left[\beta \frac{\partial u_{t+1} / \partial D_{H t+1}^{F}}{\partial u_{t} / \partial C_{H t}}-\Gamma_{t, t+1} \frac{Q_{t+1} \hat{P}_{F t+1}^{D F} \hat{P}_{H t+1}}{\hat{P}_{F t+1}(1-\tau)}\left(\frac{\partial \Delta_{H t+1}^{F}}{\partial D_{H t+1}^{F}}-\left(1-\delta_{D}\right)\left(1+\frac{\partial \Delta_{H t+1}^{F}}{\partial d_{H t+1}^{F}}\right)\right)\right] \\
& \frac{\partial u_{t}}{\partial L_{H t}}+\hat{W}_{H t} \frac{\partial u_{t}}{\partial C_{H t}}=0 \\
& \hat{P}_{H t}^{D H}\left(1+\frac{\partial \Lambda_{H t}^{N H}}{\partial I_{H t}^{N H}}\right)=E_{t}\left[\Gamma_{t, t+1}\left(\hat{R}_{H t+1}^{N H}-\hat{P}_{H t+1}^{D H}\left(\frac{\partial \Lambda_{H t+1}^{N H}}{\partial K_{H t+1}^{N H}}-(1-\delta)\left(1+\frac{\partial \Lambda_{H t+1}^{N H}}{\partial I_{H t+1}^{N H}}\right)\right)\right)\right] \\
& \frac{Q_{t} \hat{P}_{F t}^{D F} \hat{P}_{H t}}{\hat{P}_{F t}(1-\tau)}\left(1+\frac{\partial \Lambda_{H t}^{N F}}{\partial I_{H t}^{N F}}\right) \\
& =E_{t}\left[\Gamma_{t, t+1}\left(\hat{R}_{H t+1}^{N F}-\frac{Q_{t+1} \hat{P}_{F t+1}^{D F} \hat{P}_{H t+1}}{(1-\tau) \hat{P}_{F t+1}}\left(\frac{\partial \Lambda_{H t+1}^{N F}}{\partial K_{H t+1}^{N F}}-(1-\delta)\left(1+\frac{\partial \Lambda_{H t+1}^{N F}}{\partial I_{H t+1}^{N F}}\right)\right)\right)\right] \\
& \hat{P}_{H t}^{D H}\left(1+\frac{\partial \Lambda_{H t}^{D H}}{\partial I_{H t}^{D H}}\right)=E_{t}\left[\Gamma_{t, t+1}\left(\hat{R}_{H t+1}^{D H}-\hat{P}_{H t+1}^{D H}\left(\frac{\partial \Lambda_{H t+1}^{D H}}{\partial K_{H t+1}^{D H}}-(1-\delta)\left(1+\frac{\partial \Lambda_{H t+1}^{D H}}{\partial I_{H t+1}^{D H}}\right)\right)\right)\right] \\
& \frac{Q_{t} \hat{P}_{F t}^{D F} \hat{P}_{H t}}{\hat{P}_{F t}(1-\tau)}\left(1+\frac{\partial \Lambda_{H t}^{D F}}{\partial I_{H t}^{D F}}\right) \\
& =E_{t}\left[\Gamma_{t, t+1}\left(\hat{R}_{H t+1}^{D F}-\frac{Q_{t+1} \hat{P}_{F t+1}^{D F} \hat{P}_{H t+1}}{(1-\tau) \hat{P}_{F t+1}}\left(\frac{\partial \Lambda_{H t+1}^{D F}}{\partial K_{H t+1}^{D F}}-(1-\delta)\left(1+\frac{\partial \Lambda_{H t+1}^{D F}}{\partial I_{H t+1}^{D F}}\right)\right)\right)\right] \\
& \frac{1}{1+i_{t}}+\Phi B_{H t+1}=E_{t}\left[\Gamma_{t, t+1} \frac{\hat{P}_{H t+1}^{D H}}{\hat{P}_{H t}^{D H}}\right]
\end{aligned}
$$

Symmetric conditions hold in the Foreign country. From Walras' law, one equation is redundant. We eliminate the Foreign country's budget constraint from our equation system. So equations in the Foreign

\footnotetext{
${ }^{34}$ It is useful to note that this term is negative.
} 
country are

$$
\begin{aligned}
& D_{F t+1}^{F}=\left(1-\delta_{D}\right) D_{F t}^{F}+d_{F t}^{F} \\
& D_{F t+1}^{H}=\left(1-\delta_{D}\right) D_{F t}^{H}+d_{F t}^{H} \\
& K_{F t+1}^{N F}=(1-\delta) K_{F t}^{N F}+I_{F t}^{N F} \\
& K_{F t+1}^{N H}=(1-\delta) K_{F t}^{N H}+I_{F t}^{N H} \\
& K_{F t+1}^{D F}=(1-\delta) K_{F t}^{D F}+I_{F t}^{D F} \\
& K_{F t+1}^{D H}=(1-\delta) K_{F t}^{D H}+I_{F t}^{D H} \\
& \hat{P}_{F t}=\left(\hat{P}_{F t}^{D F}\right)^{\omega_{2}}\left(\frac{\hat{P}_{H t}^{D H} \hat{P}_{F t}}{Q_{t} \hat{P}_{H t}(1-\tau)}\right)^{1-\omega_{1}-\omega_{2}} \\
& \hat{P}_{F t}^{D F}\left(1+\frac{\partial \Delta_{F t}^{F}}{\partial d_{F t}^{F}}\right)=E_{t}\left[\beta \frac{\partial u_{t+1}^{*} / \partial D_{F t+1}^{F}}{\partial u_{t}^{*} / \partial C_{F t}}-\Gamma_{t, t+1}^{*} \hat{P}_{F t+1}^{D F}\left(\frac{\partial \Delta_{F t+1}^{F}}{\partial D_{F t+1}^{F}}-\left(1-\delta_{D}\right)\left(1+\frac{\partial \Delta_{F t+1}^{F}}{\partial d_{F t+1}^{F}}\right)\right)\right] \\
& \frac{\hat{P}_{H t}^{D H} \hat{P}_{F t}}{Q_{t} \hat{P}_{H t}(1-\tau)}\left(1+\frac{\partial \Delta_{F t}^{H}}{\partial d_{F t}^{H}}\right) \\
& =E_{t}\left[\beta \frac{\partial u_{t+1}^{*} / \partial D_{F t+1}^{H}}{\partial u_{t}^{*} / \partial C_{F t}}-\Gamma_{t, t+1}^{*} \frac{\hat{P}_{H t+1}^{D H} \hat{P}_{F t+1}}{Q_{t+1} \hat{P}_{H t+1}(1-\tau)}\left(\frac{\partial \Delta_{F t+1}^{H}}{\partial D_{F t+1}^{H}}-\left(1-\delta_{D}\right)\left(1+\frac{\partial \Delta_{F t+1}^{H}}{\partial d_{F t+1}^{H}}\right)\right)\right] \\
& \frac{\partial u_{t}^{*}}{\partial L_{F t}}+\hat{W}_{F t} \frac{\partial u_{t}^{*}}{\partial C_{F t}}=0 \\
& \hat{P}_{F t}^{D F}\left(1+\frac{\partial \Lambda_{F t}^{N F}}{\partial I_{F t}^{N F}}\right)=E_{t}\left[\Gamma_{t, t+1}^{*}\left(\hat{R}_{F t+1}^{N F}-\hat{P}_{F t+1}^{D F}\left(\frac{\partial \Lambda_{F t+1}^{N F}}{\partial K_{F t+1}^{N F}}-(1-\delta)\left(1+\frac{\partial \Lambda_{F t+1}^{N F}}{\partial I_{F t+1}^{N F}}\right)\right)\right)\right] \\
& \frac{\hat{P}_{H t}^{D H} \hat{P}_{F t}}{Q_{t} \hat{P}_{H t}(1-\tau)}\left(1+\frac{\partial \Lambda_{F t}^{N H}}{\partial I_{F t}^{N H}}\right) \\
& =E_{t}\left[\Gamma_{t, t+1}^{*}\left(\hat{R}_{F t+1}^{N H}-\frac{\hat{P}_{H t+1}^{D H} \hat{P}_{F t+1}}{Q_{t+1}(1-\tau) \hat{P}_{H t+1}}\left(\frac{\partial \Lambda_{F t+1}^{N H}}{\partial K_{F t+1}^{N H}}-(1-\delta)\left(1+\frac{\partial \Lambda_{F t+1}^{N H}}{\partial I_{F t+1}^{N H}}\right)\right)\right)\right] \\
& \hat{P}_{F t}^{D F}\left(1+\frac{\partial \Lambda_{F t}^{D F}}{\partial I_{F t}^{D F}}\right)=E_{t}\left[\Gamma_{t, t+1}^{*}\left(\hat{R}_{F t+1}^{D F}-\hat{P}_{F t+1}^{D F}\left(\frac{\partial \Lambda_{F t+1}^{D F}}{\partial K_{F t+1}^{D F}}-(1-\delta)\left(1+\frac{\partial \Lambda_{F t+1}^{D F}}{\partial I_{F t+1}^{D F}}\right)\right)\right)\right] \\
& \frac{\hat{P}_{H t}^{D H} \hat{P}_{F t}}{Q_{t} \hat{P}_{H t}(1-\tau)}\left(1+\frac{\partial \Lambda_{F t}^{D H}}{\partial I_{F t}^{D H}}\right) \\
& =E_{t}\left[\Gamma_{t, t+1}^{*}\left(\hat{R}_{F t+1}^{D H}-\frac{\hat{P}_{H t+1}^{D H} \hat{P}_{F t+1}}{Q_{t+1}(1-\tau) \hat{P}_{H t+1}}\left(\frac{\partial \Lambda_{F t+1}^{D H}}{\partial K_{F t+1}^{D H}}-(1-\delta)\left(1+\frac{\partial \Lambda_{F t+1}^{D H}}{\partial I_{F t+1}^{D H}}\right)\right)\right)\right] \\
& \frac{1}{1+i_{t}}+\Phi B_{F t+1}=E_{t}\left[\Gamma_{t, t+1}^{*} \frac{\hat{P}_{F t+1}^{D H}}{\hat{P}_{F t}^{D H}}\right]
\end{aligned}
$$




\section{Market Clearing Conditions}

The model is closed with market clearing conditions

$Y_{H t}^{N}=C_{H t}$

$Y_{F t}^{N}=C_{F t}$

$Y_{H t}^{D}=d_{H t}^{H}+\Delta_{H t}^{H}+I_{H t}^{N H}+\Lambda_{H t}^{N H}+I_{H t}^{D H}+\Lambda_{H t}^{D H}+\frac{1}{2} \Phi B_{H t+1}^{2}+\frac{d_{F t}^{H}+\Delta_{F t}^{H}+I_{F t}^{N H}+\Lambda_{F t}^{N H}+I_{F t}^{D H}+\Lambda_{F t}^{D H}+\frac{1}{2} \Phi B_{F t+1}^{2}}{1-\tau}$

$Y_{F t}^{D}=d_{F t}^{F}+\Delta_{F t}^{F}+\frac{d_{H t}^{F}+\Delta_{H t}^{F}}{1-\tau}+I_{F t}^{N F}+\Lambda_{F t}^{N F}+I_{F t}^{D F}+\Lambda_{F t}^{D F}+\frac{I_{H t}^{N F}+\Lambda_{H t}^{N F}+I_{H t}^{D F}+\Lambda_{H t}^{D F}}{1-\tau}$

$L_{H t}^{N}+L_{H t}^{D}=L_{H t}$

$L_{F t}^{N}+L_{F t}^{D}=L_{F t}$

$B_{H t}+B_{F t}=0$.

There are 10 equations in the nondurable good sector (from equation (A.2.1) to (A.2.10)), and 10 equations in the durable good sector (from equation (A.2.11) to (A.2.20)). We have 31 equations from the household's problem (from equation (A.2.21) to (A.2.51)). In addition, we have 7 equations in this section (from equation (A.2.52) to (A.2.58)). As a total, we have 58 equations. Those equations define equilibrium conditions for the following 58 variables.

16 variables in nondurable good sector:

$$
\left[\begin{array}{llllllll}
\hat{R}_{H t}^{N H} & \hat{R}_{H t}^{N F} & \hat{W}_{H t} & K_{H t}^{N H} & K_{H t}^{N F} & K_{H t}^{N} & L_{H t}^{N} & Y_{H t}^{N} \\
\hat{R}_{F t}^{N F} & \hat{R}_{F t}^{N H} & \hat{W}_{F t} & K_{F t}^{N F} & K_{F t}^{N H} & K_{F t}^{N} & L_{F t}^{N} & Y_{F t}^{N}
\end{array}\right]
$$

16 variables in durable good sector

$$
\left[\begin{array}{cccccccc}
\hat{P}_{H t}^{D H} & \hat{R}_{H t}^{D H} & \hat{R}_{H t}^{D F} & K_{H t}^{D H} & K_{H t}^{D F} & K_{H t}^{D} & L_{H t}^{D} & Y_{H t}^{D} \\
\hat{P}_{F t}^{D F} & \hat{R}_{F t}^{D F} & \hat{R}_{F t}^{D H} & K_{F t}^{D F} & K_{F t}^{D H} & K_{F t}^{D} & L_{F t}^{D} & Y_{F t}^{D}
\end{array}\right]
$$

26 variables in household's problem

$$
\begin{aligned}
& {\left[\begin{array}{llllllllllll}
D_{H t}^{H} & d_{H t}^{H} & D_{H t}^{F} & d_{H t}^{F} & I_{H t}^{N H} & I_{H t}^{N F} & I_{H t}^{D H} & I_{H t}^{D F} & C_{H t} & \hat{P}_{H t} & \hat{B}_{H t} & L_{H t} \\
D_{F t}^{F} & d_{F t}^{F} & D_{F t}^{H} & d_{F t}^{H} & I_{F t}^{N F} & I_{F t}^{N H} & I_{F t}^{D F} & I_{F t}^{D H} & C_{F t} & \hat{P}_{F t} & \hat{B}_{F t} & L_{F t} \\
i_{t} & Q_{t}
\end{array}\right] .}
\end{aligned}
$$




\section{A.2.2 Solving Steady State of Benchmark Model}

From the household's problem, we can solve the return to capital

$$
\hat{R}_{H}^{N H}=\hat{R}_{H}^{D H}=\hat{P}_{H}^{D H}\left[\frac{1}{\beta}-(1-\delta)\right] .
$$

In the steady state, the return to capital in the nondurable-good sector is the same as that in the durablegood sector. This result is intuitive since there is no long-run restriction on moving capital between these two sectors. Similarly, we can find that the returns to Foreign capital goods are also the same across these two sectors

$$
\hat{R}_{H}^{N F}=\hat{R}_{H}^{D F}=\frac{\hat{R}_{H}^{N H}}{1-\tau}
$$

Because of the trade cost, the return to the Foreign-good capital has to be higher than the return to the Home-good capital. As shown in the calibration, this trade cost generates home bias endogenously in the durable good sector.

Substituting equations (A.2.59) and (A.2.60) into the definitions of $\hat{R}_{H}^{N}$ and $\hat{R}_{H}^{D}$, we find $\hat{R}_{H}^{N}=\hat{R}_{H}^{D}$, which says that the return to aggregate capital is the same in those two sectors. Now we assume that the production structure is the same in these two sectors by equalizing the capital share in both sectors $(\chi=\epsilon) .{ }^{35}$ If we compare equations (A.2.1) and (A.2.11), the above results and the assumption of equal capital share imply $\hat{P}_{H}^{D H}=1 .^{36}$ That is, in the steady state, durable goods have the same price as nondurable goods. The intuition comes from the fact that the production costs of durable and nondurable goods are the same in the steady state: the same production structure, same cost of capital and same cost of labor. This result gives us the solution to the Home-good capital return

$$
\hat{R}_{H}^{N H}=\hat{R}_{H}^{D H}=\left[\frac{1}{\beta}-(1-\delta)\right]
$$

The return to Foreign-good capital can be solved from equation (A.2.60). The returns to the aggregate capital in both sectors can be solved from their definitions.

$$
\begin{gathered}
\hat{R}_{H}^{N}=\left[\alpha\left(\hat{R}_{H}^{N H}\right)^{1-\gamma}+(1-\alpha)\left(\hat{R}_{H}^{N F}\right)^{1-\gamma}\right]^{\frac{1}{1-\gamma}} \\
\hat{R}_{H}^{D}=\left[\alpha\left(\hat{R}_{H}^{D H}\right)^{1-\gamma}+(1-\alpha)\left(\hat{R}_{H}^{D F}\right)^{1-\gamma}\right]^{\frac{1}{1-\gamma}} .
\end{gathered}
$$

\footnotetext{
${ }^{35}$ This assumption is also used in other two-sector models, for instance, Erceg and Levin (2006), Whelan (2003).

${ }^{36}$ The steady-state productivity shock is equal to 1 in both sectors.
} 
Now we can solve the wage from equation (A.2.1)

$$
\hat{W}_{H}=\left[\left(\hat{R}_{H}^{N}\right)^{-\chi} \chi^{\chi}(1-\chi)^{1-\chi}\right]^{\frac{1}{1-\chi}}
$$

So far, all prices have been solved and we move to solve quantities of the model.

The utility function in our model is too complicated for us to obtain a recursive solution to quantity variables. Instead we solve them numerically. From the labor demand function in both sectors (equations (A.2.5) and (A.2.15)), we have

$$
L_{H}=L_{H}^{N}+L_{H}^{D}=(1-\chi)\left(Y_{H}^{N}+Y_{H}^{D}\right) / \hat{W}_{H},
$$

in which we used the condition of $\chi=\epsilon$. We assume that in the steady state, labor supply is one third. This gives us the first equation that we will use to solve some variables numerically

$$
C_{H}+Y_{H}^{D}=\frac{\hat{W}_{H}}{3(1-\epsilon)}
$$

We also used the market clearing condition of nondurable goods $\left(C_{H}=Y_{H}^{N}\right)$ to get the above equation.

In the symmetric equilibrium, the real exchange rate $Q_{t}$ is equal to one. The prices of durable goods are the same across countries $\hat{P}_{H}^{D H}=\hat{P}_{F}^{D F}$. From the household's first order conditions (equations (A.2.29) and (A.2.30)), we have

$$
\begin{aligned}
& \frac{1}{\beta}-\left(1-\delta_{D}\right)=\frac{\partial u_{t} / \partial D_{H}^{H}}{\partial u_{t} / \partial C_{H}} \\
& \frac{1}{1-\tau}\left[\frac{1}{\beta}-\left(1-\delta_{D}\right)\right]=\frac{\partial u_{t} / \partial D_{H}^{F}}{\partial u_{t} / \partial C_{H}} .
\end{aligned}
$$

From the market clearing condition of durable goods, we have

$$
Y_{H}^{D}=\delta_{D}\left(D_{H}^{H}+\frac{D_{H}^{F}}{1-\tau}+\frac{\delta \chi}{\hat{R}_{H}^{N}}\left(C_{H}+Y_{H}^{D}\right)\left[\alpha\left(\frac{\hat{R}_{H}^{N H}}{\hat{R}_{H}^{N}}\right)^{-\gamma}+\frac{1-\alpha}{1-\tau}\left(\frac{\hat{R}_{H}^{N F}}{\hat{R}_{H}^{N}}\right)^{-\gamma}\right]\right)
$$

From the tradeoff between consumption and labor, we have

$$
\frac{\partial u_{t}}{\partial L_{H t}}+\hat{W}_{H t} \frac{\partial u_{t}}{\partial C_{H t}}=0 .
$$

Equations (A.2.66), (A.2.67), (A.2.68), (A.2.69) and (A.2.70) are used to solve jointly for consumption 
$\left(C_{H}\right)$, durable output $\left(Y_{H}^{D}\right)$, stock of home-good durable consumption $\left(D_{H}^{H}\right)$, stock of foreign-good durable consumption $\left(D_{H}^{F}\right)$ and parameter $\rho . \rho$ is chosen such that the steady state labor supply is one third. With solutions to these variables, we can solve other variables recursively.

$$
\begin{aligned}
& Y_{H}^{N}=C_{H} \\
& K_{H}^{N}=\frac{\epsilon}{\hat{R}_{H}^{N}} Y_{H}^{N} \\
& K_{H}^{N H}=\alpha\left(\frac{\hat{R}_{H}^{N H}}{\hat{R}_{H}^{N}}\right)^{-\gamma} K_{H}^{N} \\
& K_{H}^{N F}=(1-\alpha)\left(\frac{\hat{R}_{H}^{N F}}{\hat{R}_{H}^{N}}\right)^{-\gamma} K_{H}^{N} \\
& K_{H}^{N}=\chi Y_{H}^{N} / \hat{R}_{H}^{N} \\
& L_{H}^{N}=(1-\chi) Y_{H}^{N} / \hat{W}_{H} \\
& K_{H}^{D H}=\alpha\left(\frac{\hat{R}_{H}^{D H}}{\hat{R}_{H}^{D}}\right)^{-\gamma} K_{H}^{D} \\
& K_{H}^{D F}=(1-\alpha)\left(\frac{\hat{R}_{H}^{D F}}{\hat{R}_{H}^{D}}\right)^{-\gamma} K_{H}^{D} \\
& K_{H}^{D}=\epsilon Y_{H}^{D} / \hat{R}_{H}^{D} \\
& L_{H}^{D}=(1-\epsilon) Y_{H}^{D} / \hat{W}_{H} \\
& d_{H}^{H}=\delta_{D} D_{H}^{H} \\
& d_{H}^{F}=\delta_{D} D_{H}^{F} \\
& I_{H}^{N H}=\delta K_{H}^{N H} \\
& I_{H}^{N F}=\delta K_{H}^{N F} \\
& I_{H}^{D H}=\delta K_{H}^{D H} \\
& I_{H}^{D F}=\delta K_{H}^{D F} \\
& B_{H}=0 \\
& i=\frac{1}{\beta}-1 \\
&
\end{aligned}
$$




\section{A.3 Elasticity Puzzle}

In this section, we use a simple example to give more details about the elasticity puzzle in the literature. Suppose the final output is a CES composite of Home and Foreign goods. From the CES aggregation function, we can find demands for imports and the Home goods

$$
\begin{array}{r}
Y_{H t}^{F}=(1-\alpha)\left(\frac{P_{H t}^{F}}{P_{H t}}\right)^{-\gamma} Y_{H t} \\
Y_{H t}^{H}=\alpha\left(\frac{P_{H t}^{H}}{P_{H t}}\right)^{-\gamma} Y_{H t},
\end{array}
$$

where $Y_{H t}^{F}$ is the demand for Foreign goods. $P_{H t}^{F}$ is the price of Foreign goods and $P_{H t}$ is the aggregate price. $Y_{H t}$ is the aggregate demand. $Y_{H t}^{H}$ is the demand for Home goods and $P_{H t}^{H}$ is the price of Home goods. Dividing one of the above equations by the other, we have

$$
\frac{Y_{H t}^{F}}{Y_{H t}^{H}}=\frac{1-\alpha}{\alpha}\left(\frac{P_{H t}^{F}}{P_{H t}^{H}}\right)^{-\gamma}
$$

By definition, the elasticity of substitution between the Home and Foreign goods is

$$
-\frac{d \log \left(Y_{H t}^{F} / Y_{H t}^{H}\right)}{d \log \left(P_{H t}^{F} / P_{H t}^{H}\right)}=\gamma
$$

If $\log \left(Y_{H t}^{F} / Y_{H t}^{H}\right)$ and $\log \left(P_{H t}^{F} / P_{H t}^{H}\right)$ are stationary, we can regress $\log \left(Y_{H t}^{F} / Y_{H t}^{H}\right)$ on $\log \left(P_{H t}^{F} / P_{H t}^{H}\right)$ to find the elasticity. This exercise has been done with industrial-level data in several papers, for instance, Reinert and Roland-Holst (1992), Blonigen and Wilson (1999), Reinert and Shiells (1993). The estimates from quarterly data are usually small with an average of around 0.85. In aggregate models, this parameter is usually calibrated in the range between 0.5 to 2 . Bergin (2006) estimates a two-country general equilibrium model. His estimate is 1.13. Heathcote and Perri (2002) also estimate this parameter with aggregate data and find an estimate of 0.9. So at the business cycle frequency, the empirical findings both at disaggregate and aggregate levels point to a small elasticity of substitution between the home and foreign goods.

Ruhl (2005) uses the method of regression to find the elasticity of substitution in his model. Drozd and Nosal (2007) propose a measurement that follows this spirit, but they do not run the regression. Instead, from equation (A.3.3), the standard deviation of $\log \left(Y_{H t}^{F} / Y_{H t}^{H}\right)$ divided by the standard deviation of $\log \left(P_{H t}^{F} / P_{H t}^{H}\right)$ is also equal to $\gamma$ under the model's setup. We use both methods in our benchmark model and find our results are robust.

The second strand of literature estimates the elasticity of substitution through the (long-run) response 
of trade flows to permanent relative price changes. One example is a tariff reduction. Let's assume that the rate of tariff is $\tau$ and the law of one price holds after taking into account the tariff, that is,

$$
P_{H t}^{F}=(1+\tau) S_{t} P_{F t}^{F},
$$

where $P_{F t}^{F}$ is the price of foreign goods in the foreign country and $S_{t}$ is the exchange rate. Substitute this to equation (A.3.3), we have

$$
\begin{aligned}
\frac{Y_{H t}^{F}}{Y_{H t}^{H}} & =\frac{1-\alpha}{\alpha}\left(\frac{P_{H t}^{F}}{P_{H t}^{H}}\right)^{-\gamma} \\
& =\frac{1-\alpha}{\alpha}\left((1+\tau) S_{t} \frac{P_{F t}^{F}}{P_{H t}^{H}}\right)^{-\gamma} .
\end{aligned}
$$

We use variables without time scripts to denote their steady state values. From equation (A.3.6), we have

$$
\Delta \log \left(\frac{Y_{H}^{F}}{Y_{H}^{H}}\right)=-\gamma \Delta \log (1+\tau)-\gamma \Delta \log \left(\frac{S P_{F}^{F}}{P_{H}^{H}}\right)
$$

Under the assumption that there is no change of relative price $\frac{S P_{F}^{F}}{P_{H}^{H}}$, the increase of trade share is determined by the change of tariff and the elasticity of substitution $\gamma$. The equation is identified by regressing it across different industries

$$
\Delta \log \left(\frac{Y_{i H}^{F}}{Y_{i H}^{H}}\right)=\alpha-\gamma \Delta \log \left(1+\tau_{i}\right)+\varepsilon_{i}
$$

where $i$ is the index of industries. The estimates from industrial level data usually give a large $\gamma$, which ranges from 6 to 15. For instance, see Feenstra and Levinsohn (1995), Head and Ries (2001), and Lai and Trefler (2002). Yi (2003) shows that the trade share of output increased substantially for a small decrease in tariffs. He points out that to replicate those findings in a general equilibrium model, the elasticity of substitution between the home and foreign goods must be very large. These results are strikingly different from those obtained from first stand of literature, though under the setup of our example, they are estimating the same parameter $\gamma$. This discrepancy has been labeled as elasticity puzzle in the literature.

\section{A.4 Backus-Smith Puzzle}

In this section, we describe how to calculate the utility-based real exchange rate used in Section 5.3. The calculation is straightforward if we ignore the frictions in the economy. Suppose that the household is 
renting the durable consumption from a competitive market instead of owning it. The rent cost in terms of the nondurable goods will be the marginal utility of durable consumption divided by the marginal utility of nondurable consumption

$$
\begin{gathered}
\hat{P}_{H t}^{R H}=\frac{\partial u_{H t} / \partial D_{H t}^{H}}{\partial u_{H t} / \partial C_{H t}} \\
\hat{P}_{H t}^{R F}=\frac{\partial u_{H t} / \partial D_{H t}^{F}}{\partial u_{H t} / \partial C_{H t}},
\end{gathered}
$$

where $\hat{P}_{H t}^{R H}$ and $\hat{P}_{H t}^{R F}$ are respectively the rental prices for Home- and Foreign-good durable consumption. All prices with a hat are in terms of nondurable goods.

The aggregate durable consumption stock is a CES function of the Home- and Foreign-good durable consumption stocks

$$
D_{H t}=\left[\psi^{\frac{1}{\theta}}\left(D_{H t}^{H}\right)^{\frac{\theta-1}{\theta}}+(1-\psi)^{\frac{1}{\theta}}\left(D_{H t}^{F}\right)^{\frac{\theta-1}{\theta}}\right]^{\frac{\theta}{\theta-1}}
$$

where $\psi$ is the weight of Home durable goods in the durable consumption composite, and $\theta$ is the elasticity of substitution between the Home and Foreign durable goods. It is straightforward for us to find the shadow price of $D_{H t}$

$$
\hat{P}_{H t}^{R}=\left[\psi\left(\hat{P}_{H t}^{R H}\right)^{1-\theta}+(1-\psi)\left(\hat{P}_{H t}^{R F}\right)^{1-\theta}\right]^{\frac{1}{1-\theta}}
$$

The utility consumption is a CES function of durable and nondurable consumption

$$
U C_{H t}=\left(\mu^{\frac{1}{\zeta}} D_{H t}^{\frac{\zeta-1}{\zeta}}+(1-\mu)^{\frac{1}{\zeta}} C_{H t}^{\frac{\zeta-1}{\zeta}}\right)^{\frac{\zeta}{\zeta-1}}
$$

It is easy for us to find the utility-based price index

$$
\hat{P}_{H t}^{U C}=\left[\mu\left(\hat{P}_{H t}^{R}\right)^{1-\zeta}+(1-\mu)\right]^{\frac{1}{1-\zeta}} .
$$

Symmetric equations hold in the Foreign country, from which we can find the utility-based price index in the Foreign country $\hat{P}_{F t}^{U C}$. The utility-based real exchange rate is

$$
Q_{t}^{U C}=\frac{Q_{t} \hat{P}_{F t}^{U C} \hat{P}_{H t}}{\hat{P}_{H t}^{U C} \hat{P}_{F t}}
$$


where $Q_{t}$ is the CPI-based real exchange rate. $\hat{P}_{H t}$ is the consumer price index in the Home country and $\hat{P}_{F t}$ is the consumer price index in the Foreign country. To see how to get this equation, it is useful to note that

$$
\begin{aligned}
Q_{t}^{U C} & =\frac{S_{t} P_{F t}^{U C}}{P_{H t}^{U C}} \\
& =\frac{\frac{S_{t} P_{F t}}{P_{H t}} \frac{P_{H t}}{P_{F t}} \frac{P_{F t}^{U C}}{P_{F t}^{N}} P_{F t}^{N}}{\frac{P_{H t}^{U C}}{P_{H t}^{N}} P_{H t}^{N}} \\
& =\frac{Q_{t} \hat{P}_{F t}^{U C} \hat{P}_{H t}}{\hat{P}_{H t}^{U C} \hat{P}_{F t}},
\end{aligned}
$$

where all prices without a hat are nominal prices and $P_{H t}^{N}\left(P_{F t}^{N}\right)$ is the nominal price of Home (Foreign) nondurable goods. 